No. 1531

\title{
Lipoproteomics \\ Environmental and Genetic Factors Affecting High-Density Lipoprotein (HDL)
}

\author{
Stefan Ljunggren
}

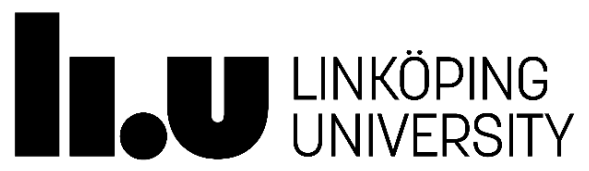

Occupational and Environmental Medicine

Department of Clinical and Experimental Medicine

Faculty of Health Sciences, Linköping University

SE-581 85 Linköping, Sweden 
(C) Stefan Ljunggren, 2016

Paper I, published in Proteomics - Clinical Applications, is reprinted with permission from John Wiley and Sons.

Paper II, published in Biochimica et Biophysica Acta - Molecular and Cell Biology of Lipids, is reprinted with permission from Elsevier.

Paper III, published in Environment International, is reprinted with permission from Elsevier.

ISBN: 978-91-7685-709-0

ISSN: 0345-0082

Cover was created by the author and produced by Per Lagman, LiU-Tryck

Printed by LiU-Tryck, Linköping, 2016 
To my wife Therese

For being my unwavering friend and companion on this journey. I wouldn't be here today without You 
SUPERVISOR

\section{Mats Lindahl}

Department of Clinical and Experimental Medicine Linköping University

Sweden

\section{CO-SUPERVISORS}

\section{Gun Wingren}

Department of Clinical and Experimental Medicine Linköping University

Sweden

\section{Helen Karlsson}

Occupational and Environmental Medicine

Region Östergötland

Sweden

\section{Jan Albert Kuivenhoven}

Department of Pathology and Medical Biology

Groningen University

The Netherlands 


\section{Abstract}

Lipoprotein particles act as lipid transporters in the blood stream, and measuring cholesterol content in specific subclasses of lipoprotein particles has long been, and still is, a frequently used tool to estimate the risk of cardiovascular disease (CVD). High-density lipoprotein (HDL) is a subclass of lipoproteins often regarded as providing protection against CVD via several functions including reverse cholesterol transport and antiinflammatory capacities. However, the precise relationship between HDL cholesterol levels and health outcome is still unclear. Lately, new approaches to study HDL composition and function have therefore become more important.

HDL function is to a large extent dependent on its proteome, containing more than 100 proteins. Investigating the proteome in individuals with altered gene expression for HDLassociated proteins or with known exposure to environmental contaminants may reveal new insights into how HDL metabolism is affected by various factors. This is of interest in order to better understand the role of HDL in CVD.

Papers I and II focus on two different mutations in a structural HDL protein, apolipoprotein A-I (L202P and K131del), and one mutation in the scavenger receptor class B-1 (P297S), which is involved in selective lipid uptake of cholesterol mainly into hepatocytes and adrenal cells. The HDL proteome was analyzed using two-dimensional gel electrophoresis and mass spectrometry. The L202P mutation was identified in HDL of the heterozygote carriers together with a significant decrease of apolipoprotein $\mathrm{E}$ and increased zinc-alpha-2-glycoprotein. By contrast, the second apolipoprotein A-I mutation (K131del) was associated with significantly elevated alpha-1-antitrypsin and transthyretin levels. Protein analyses of the scavenger receptor class B1 P297S heterozygotes showed a significant increase in HDL apoL-1 along with increased free apoE. The carriers showed no difference in anti-oxidative capability but a significant increase in apoA-I methionine oxidation.

Papers III and IV focus on persistent organic pollutants that may influence HDL composition and function. These compounds accumulate in humans, and exposure has been linked to an increased risk of CVD. To provide a better understanding of the HDL system in relation to pollutants, a population living in a contaminated area was studied. Persistent organic pollutants in isolated HDL were quantified using high-resolution gas chromatography mass spectrometry and significantly increased levels were found in individuals with CVD as compared to healthy controls. Furthermore, there was a significant negative association between the pollutants and paraoxonase- 1 anti-oxidant activity. Studying the proteome with nano-liquid chromatography tandem mass 
spectrometry led to the identification of 118 proteins in HDL, of which ten were significantly associated with the persistent organic pollutants.

In summary, the present studies demonstrate protein pattern alterations in HDL associated with inherited genetic variants or pollutant exposure. The studies also provide a set of methods that are useful tools to further comprehend the complexity of lipoprotein metabolism and function. The results are important in order to improve our understanding of HDL in CVD and to explain an increased risk of CVD associated with exposure to organic pollutants. 


\section{Populärvetenskaplig sammanfattning}

\section{Förändringar av proteinuttryck $i$ högdensitetslipoprotein till följd av förändringar $i$ arvsmassan eller halter av miljögifter}

Lipoproteiner är små partiklar som består av fetter och proteiner. Dessa partiklar fungerar som kroppens huvudsakliga bärare av olika fetter i blodbanan. Högdensitets-lipoprotein (HDL) är en speciell grupp av lipoproteiner som anses minska risken för hjärt- och kärlsjukdom. Dessa lipoproteiner verkar skyddande genom flera olika processer, men den mest kända är att de transporterar bort skadligt fett från kroppens celler och minskar risken för inflammation i blodkärlsväggarna. HDL kan ha ett hundratal olika proteiner bundna till sin yta och dessa bidrar till partiklarnas skyddande funktioner. Vilka proteiner som finns på partiklarnas yta bestäms av levnadsvanor och arvsmassa, men även kemikalier i omgivningen kan påverka. Proteinernas antal och deras funktion kan studeras med en mängd metoder som tillsammans kallas för lipoproteomik. Syftet med denna avhandling var att undersöka hur proteinsammansättningen i HDL påverkas av olika förändringar i arvsmassan (mutationer) och fettlösliga miljögifter.

Avhandlingen visar att proteinsammansättningen i HDL förändras till följd av mutationer samt halter av miljögifter. Gällande mutationerna upptäcktes flera proteinförändringar som bör undersökas vidare för att öka förståelsen för proteinernas funktion i partiklarna, samt om dessa förändringar innebär en ökad risk för hjärt- och kärlsjukdom. Dessutom beskrivs ett flertal lämpliga metoder som kan användas i framtida studier med mål att öka förståelsen för hur HDL skyddar mot hjärt- och kärlsjukdom. Resultaten visar även att HDL transporterar miljögifter i blodbanan och att halterna är högre hos personer med hjärt- och kärlsjukdom jämfört med friska personer. Miljögifterna påverkade även proteinsammansättningen hos HDL. Dessa fynd är viktiga eftersom människor utsätts för ett stort antal kemikalier i vardagen, men effekterna i kroppen är relativt okända. Våra resultat tyder på att HDL påverkas av miljögifter och kan vara en bidragande faktor till en ökad risk för hjärt- och kärlsjukdom.

Dessa studier av HDL är viktiga för att öka förståelsen gällande kopplingar mellan arvsmassa eller miljögifter och hjärt- och kärlsjukdom. Lipoproteomik-teknik kan bidra till ökad kunskap om HDL-partiklars struktur och funktion och kan i förlängningen leda till nya vägar att påverka HDL, med målet att minska risken för hjärt- och kärlsjukdom. 


\section{Preface}

This thesis is based on the following papers, which are referred to in the text by their Roman numerals:

I

Stefan Ljunggren, Johannes Levels, Maria Turkina, Sofie Sundberg, Andrea Bochem, Kees Hovingh, Adriaan Holleboom, Mats Lindahl, Jan Albert Kuivenhoven, Helen Karlsson.

ApoA-I mutations, L202P and K131del, in HDL from heterozygotes with low HDL-C.

Proteomics - Clinical Applications. 2014;8:241-250.

II

Stefan Ljunggren, Johannes Levels, Kees Hovingh, Adriaan Holleboom, Menno Vergeer, Letta Argyri, Christina Gkolfinopoulou, Angeliki Chroni, Jeroen Sierts, John Kastelein, Jan Albert Kuivenhoven, Mats Lindahl, Helen Karlsson.

Lipoprotein profiles in human heterozygote carriers of a functional mutation P297S in scavenger receptor class B1.

Biochimica et Biophysica Acta - Molecular and Cell Biology of Lipids. 2015;1851:15871595 .

III

Stefan Ljunggren, Ingela Helmfrid, Samira Salihovic, Bert van Bavel, Gun Wingren, Mats Lindahl, Helen Karlsson.

Persistent organic pollutants distribution in lipoprotein fractions in relation to cardiovascular disease and cancer.

Environment International. 2014;65:93-99.

IV

Stefan Ljunggren, Ingela Helmfrid, Ulf Norinder, Mats Fredriksson, Gun Wingren, Helen Karlsson, Mats Lindahl.

Persistent organic pollutants and high-density lipoprotein proteomics.

Submitted. 


\section{Table of Contents}

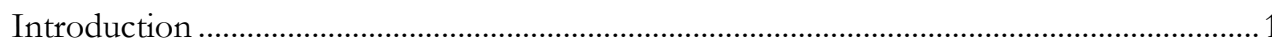

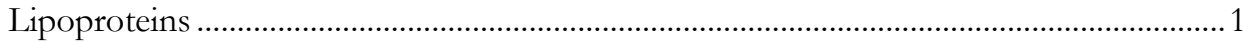

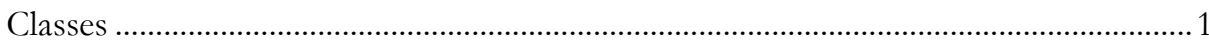

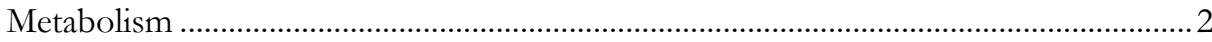

Lipoproteins in cardiovascular disease .........................................................................

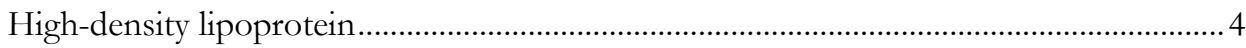

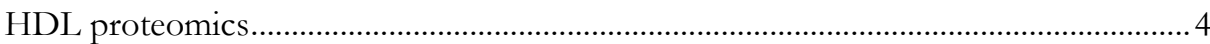

Protein isoforms

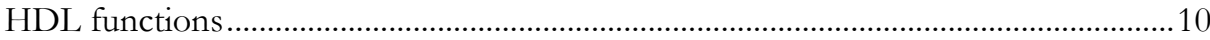

Reverse cholesterol transport............................................................................... 10

Endothelial wall function and integrity ....................................................................10

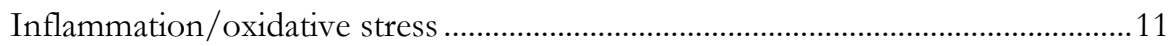

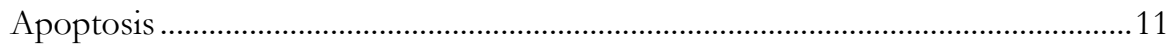

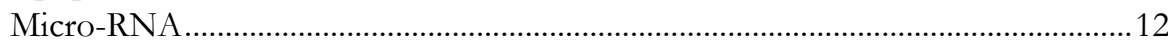

Persistent organic pollutants …………………………...........................................12

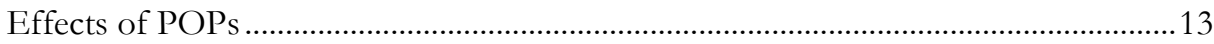

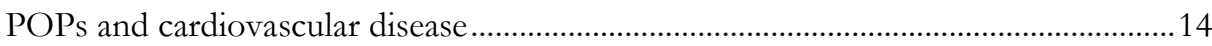

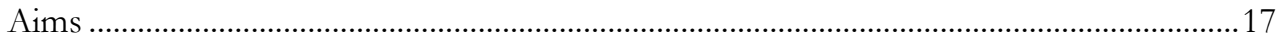

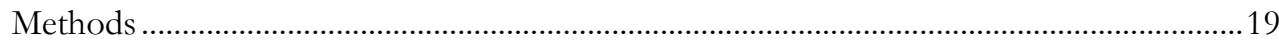

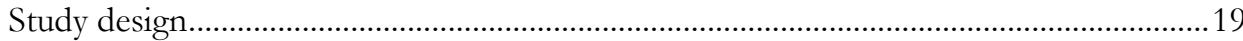

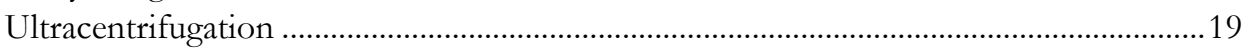

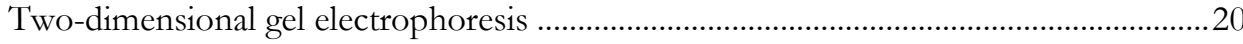

Matrix-assisted laser desorption/ionization time-of-flight mass spectrometry................21

Electrospray ionization quadrupole time-of-flight mass spectrometry ……....................22

Nano-liquid chromatography tandem mass spectrometry ................................................23

Data processing after nLC-MS/MS ............................................................................24

Analysis of persistent organic pollutants .......................................................................2.

Paraoxonase 1 activity analysis.....................................................................................26

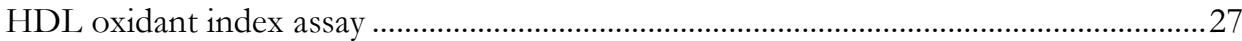

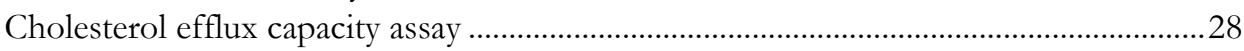

Multivariate Statistical analyses .......................................................................................2

Principal Component Analysis..................................................................................29

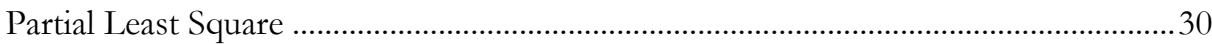

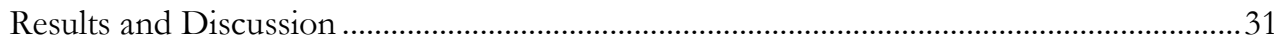

HDL in mutations causing altered HDL-C (Papers I and II) ..........................................31

Environmental pollutants and HDL (Papers III and IV) .................................................34

Concluding remarks and future perspectives ………………………………………...........

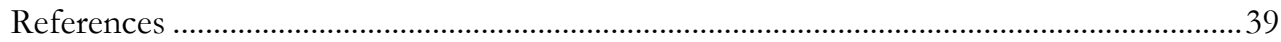

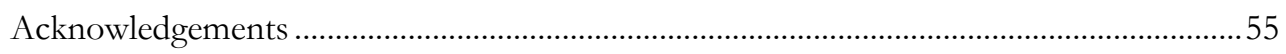




\section{Abbreviations}

\begin{tabular}{|c|c|}
\hline ABCA1 & ATP-binding cassette transporter A1 \\
\hline ABCG1 & ATP-binding cassette transporter G1 \\
\hline Apo & Apolipoprotein \\
\hline CID & Collision-induced dissociation \\
\hline CVD & Cardiovascular disease \\
\hline DDE & Dichlorodiphenyldichloroethylene \\
\hline DDT & Dichlorodiphenyltrichloroethane \\
\hline eNOS & Endothelial nitric oxide synthase \\
\hline HDL & High-density lipoprotein \\
\hline HDL-C & HDL cholesterol \\
\hline HRGC/HRMS & High resolution gas chromatography/high resolution mass spectrometry \\
\hline IDL & Intermediate-density lipoprotein \\
\hline LCAT & Phosphatidylcholine-sterol acyltransferase \\
\hline LDL & Low-density lipoprotein \\
\hline LDL-C & LDL cholesterol \\
\hline $\operatorname{miR}$ & Micro-RNA \\
\hline MPO & Myeloperoxidase \\
\hline MS & Mass spectrometry \\
\hline $\mathrm{m} / \mathrm{z}$ & Mass-to-charge ratio \\
\hline $\mathrm{NF}-x \mathrm{~B}$ & Nuclear factor-kappa B \\
\hline OCDD & Octachlorodibenzo-p-dioxin \\
\hline OCP & Organochlorine pesticide \\
\hline oxLDL & Oxidized LDL \\
\hline PBDE & Polybrominated diphenyl ether \\
\hline PCA & Principal component analysis \\
\hline PCB & Polychlorinated biphenyls \\
\hline PCDD & Polychlorinated dibenzo-p-dioxin \\
\hline PCDF & Polychlorinated dibenzofuran \\
\hline PLS & Partial least squares \\
\hline PON1 & Serum paraoxonase/arylesterase 1 \\
\hline PTMs & Post-translational modifications \\
\hline PXR & Pregnane X receptor \\
\hline RCT & Reverse cholesterol transport \\
\hline SAA & Serum amyloid A \\
\hline sumPCB & Sum of PCB congeners \\
\hline sumPCB-HC & Sum of highly chlorinated PCB congeners \\
\hline sumPOP & Sum of persistent organic pollutants \\
\hline S1P & Sphingosine-1-phosphate \\
\hline TCDD & 2,3,7,8-tetrachlorodibenzo-p-dioxin \\
\hline TTR & Transthyretin \\
\hline VLDL & Very low-density lipoprotein \\
\hline
\end{tabular}




\section{Introduction}

\section{Lipoproteins}

Lipids are a diverse group of hydrophobic molecules essential for all living organisms. Different classes of lipids serve distinct functions in the cells where phospholipids are used to build up cellular membranes, triglycerides serve as an important energy source while cholesterol is important for controlling the fluidity of cell mebranes and is used as a precursor for the synthesis of steroid hormones and bile acids. Due to the hydrophobic nature of the lipids, they cannot be easily transported in the circulatory system. Instead, they are carried in macromolecule complexes with proteins called lipoproteins. Lipoproteins are mainly spherical particles consisting of an outer monolayer of phospholipids and free cholesterol interspersed with proteins, while the lipid core consists of cholesteryl esters and triglycerides. The levels of cholesterol in the lipoproteins are used as clinical measures for estimating the risk of cardiovascular disease (CVD). The protein constituents are essential for the function and metabolism of the particles, making lipoproteomic studies an important tool to investigate lipoproteins and their relation to CVD. Lipoproteins constitute a highly dynamic and diverse collection of particles that are grouped into different classes based on their specific characteristics.

\section{Classes}

The most widely used method for lipoprotein separation from plasma is ultracentrifugation, which separates the lipoproteins based on their density. This approach has laid the foundation for the principal classification of lipoproteins into five main classes; chylomicrons, very low-density lipoprotein (VLDL), intermediate-low density lipoprotein (IDL), low-density lipoprotein (LDL) and high-density lipoprotein (HDL). Chylomicrons are the largest particles with the lowest density, while VLDL, IDL, LDL, and HDL are decreasingly smaller and with higher densities (Table 1).

Table 1. Lipoprotein main classes and characteristics [Pownall and Gotto 1999]

\begin{tabular}{cccccc}
\hline & Chylomicrons & VLDL & IDL & LDL & HDL \\
\hline Density (g/mL) & $<0.93$ & $0.95-1.006$ & $1.006-1.019$ & $1.019-1.063$ & $1.063-1.212$ \\
Diameter (nm) & $>80$ & $30-80$ & $25-35$ & 21.6 & $7.5-10$ \\
& Composition & $\mathbf{\%}$ of total dry weight) & & \\
Proteins & 2 & 8 & 19 & 22 & $40-55$ \\
Phospholipids & 7 & 18 & 19 & 22 & $25-33$ \\
Triglycerides & 86 & 55 & 23 & 6 & $3-5$ \\
Cholesterol Esters & 3 & 12 & 29 & 42 & $13-17$ \\
Free cholesterol & 2 & 7 & 9 & 8 & $4-5$ \\
\hline
\end{tabular}

The main classes can be subdivided into even smaller density subclasses. LDL has five subclasses called LDL1-5 where the most common are LDL2 and LDL3 [de Graaf et al. 
1993]. HDL has two subclasses, the larger HDL2 (average diameter $10 \mathrm{~nm}$, density 1.063 $1.125 \mathrm{~g} / \mathrm{mL}$ ) and the smaller and denser HDL3 (average diameter $7.5 \mathrm{~nm}$, density 1.125$1.212 \mathrm{~g} / \mathrm{mL})$.

HDL may be further subdivided using methods other than ultracentrifugation. With the use of non-denaturing gel electrophoresis, five different subclasses of HDL can be separated: HDL2b, HDL2a, HDL3a, HDL3b, and HDL3c, which are decreasingly smaller in size. By using two-dimensional electrophoresis, the HDL is first separated based on charge into $\alpha$-HDL and pre $\alpha$-HDL, which is spherical, as well as pre $\beta$-HDL, which is discoidal. The second separation based on size provides up to 12 different subclasses [Kontush et al. 2015].

\section{Metabolism}

Chylomicrons, VLDL, IDL, and LDL share the feature of carrying apolipoprotein (apo) B as structural apolipoprotein and are therefore called apoB-containing lipoproteins. These particles are involved in the transport of lipids from the intestine to the liver or from the liver to peripheral cells. Chylomicrons originate from the small intestine and contain apoB48 , a truncated version of full-length apoB. The expression of apoB-48 is continuous but increases after dietary intake of lipids. In the circulation, the triglyceride content of these particles is hydrolyzed by lipoprotein lipase located on the vascular endothelium, transforming the particles into smaller remnants that may be subsequently taken up by hepatocytes. VLDL contains full-length apoB, apoB-100, and is continuously produced and secreted by the liver. Similar to the chylomicrons, the triglyceride content is hydrolyzed by the action of lipoprotein lipase that reduces the size of the particles, making them denser. This action transforms the particles to IDL, whose lipid content is further hydrolyzed, transforming it into LDL particles [Nakajima et al. 2011]. VLDL and LDL mainly bind to the LDL receptor with the ligands apoB and apoE. This receptor works by internalization of the particles by receptor-mediated endocytosis followed by lipoprotein degradation and uptake of cholesterol content by the cells and recycling of the LDL receptor [Ramasamy 2014].

HDL constitutes a different type of lipoprotein particles, as compared to the apoBcontaining lipoproteins, since they contain a larger proportion of proteins and are involved in the removal of lipids from peripheral cells. HDL mainly originates from the liver where apoA-I, the main protein, is secreted in a lipid-free form. Free apoA-I are lipidated with phospholipids and free cholesterol through interaction with ATP-binding membrane cassette transport protein A1 (ABCA1) in the liver and small intestine. The free cholesterol is subsequently esterified by the action of phosphatidylcholine-sterol acyltransferase (LCAT) present on HDL, generating a lipid core consisting of cholesteryl ester. This process transforms the particles into discoidal nascent HDL particles that can interact with 
ABCA1 and thereby receive more cholesterol. Additional cholesterol loading leads to the transformation of HDL particles into mature spherical HDL3 and HDL2 that can interact with $A B C$ protein $G 1$ (ABCG1) and trigger further uptake of cholesterol from peripheral cells [Davidson and Toth 2007]. The mature HDL interacts with scavenger receptor B1 (SR-B1), which is highly expressed in liver and steroidogenic tissues such as the adrenal glands [Danilo et al. 2013]. In these tissues, SR-B1 directs the transfer of esterified cholesterol from HDL particles into the tissues. The transfer is done without internalization of the HDL particles and is therefore named selective lipid uptake. HDL may also be internalized by endocytosis, which helps deliver the non-lipid cargo of HDL [Röhrl and Stangl 2013].

In the circulation, apoB-containing lipoproteins and HDL interact through two lipid transfer proteins: cholesteryl ester transfer protein (CETP) and phospholipid transfer protein (PLTP). CETP enables the transfer of cholesteryl ester from HDL to apoBcontaining lipoproteins and the transfer of triglycerides in the opposite direction. This transfer transforms apoB-containing lipoproteins into remnants as well as facilitating the remodeling of HDL [Kingwell et al. 2014]. PLTP mediates the transfer of phospholipids from apoB-containing lipoproteins to HDL, thereby facilitating the maturation of HDL [Albers and Cheung 2004]. PLTP is also involved in fusion of HDL particles that by different processes generates both small and large particles [Settasatian et al. 2001].

\section{Lipoproteins in cardiovascular disease}

CVD is a collection of different diseases affecting the vascular system and the heart that often involves atherosclerosis, a chronic lipid driven inflammation of the vascular wall. An early mechanism of atherosclerosis is endothelial dysfunction, in which the endothelial cells increase the expression of adhesion molecules and chemoattractants with resulting infiltration of monocytes in the arterial wall. Dyslipidemia with increased levels of LDL, especially smaller and denser LDL particles, increases the risk of deposition of LDL into the intima of the vascular wall. Trapped LDL may become oxidized creating oxidized LDL particles (oxLDL), which are then scavenged by monocyte-macrophages leading to the formation of foam cells. The foam cells secrete pro-inflammatory compounds that act as a positive feedback loop since they promote further monocyte recruitment, up-regulation of scavenger receptors, macrophage proliferation as well as the migration of vascular smooth muscle cells to the intima. Foam cells, vascular smooth muscle cells, and extracellular matrix cause a thickening of the intima-media and result in atherosclerotic plaques. These plaques may reduce the blood flow or rupture, subsequently causing thrombosis [Helkin et al. 2016]. HDL is associated with protection against atherosclerosis through several different functions including reducing endothelial dysfunction, removal of oxidized lipids and acting as an anti-inflammatory mediator. 
Lipoproteins are traditionally assessed based on their content of cholesterol where clinically applicable measures include LDL cholesterol (LDL-C) and HDL cholesterol (HDL-C). It is well-established that LDL-C has a strong positive relationship with CVD and that by reducing LDL-C levels, CVD risk is reduced [Cholesterol Treatment Trialists' (CTT) Collaboration 2015]. HDL-C shows a strong inverse relationship with CVD risk but there is doubt to whether this association is causal. Numerous early epidemiological and observational reports indicated that low levels of HDL-C are related to increased risk of CVD, resulting in the view of HDL as a protective factor. The early studies were integrated into the HDL hypothesis, defined in 1975, that low levels of HDL-C increase CVD risk by impairing the removal of cholesterol from the arterial wall, which sparked the interest of increasing HDL-C to reduce CVD risk [Tariq et al. 2014, Kingwell et al. 2014]. However, genetic mutations causing increased HDL-C do not show a lower risk of CVD, and pharmaceutical interventions aiming at increasing HDL-C have not reduced the risk of developing CVD [Pownall and Gotto 2016].

Other measurements of HDL, such as the number of HDL particles, have been proposed as better measurements than HDL-C to explain the protective effects of HDL. In a high CVD risk population, the number of smaller HDL particles was a better predictor for future CVD than HDL-C [McGarrah et al. 2016]. Furthermore, the number of HDL particles was shown to be a predictor for CVD and carotid intima-media thickness in initially healthy individuals [Mackey et al. 2012]. Another measure is the ratio between apoB and apoA-I proteins (apoB/apoA-I) in plasma, integrating the apoB-containing lipoproteins and HDL in a single parameter. A meta-analysis of seven prospective studies, entailing approximately 3700 individuals, showed a significant increase in CVD risk with increasing apoB/apoA-I [Thompson and Danesh 2006] and the ratio was shown to be a significant prognostic factor for CVD in initially healthy middle-aged men [Schmidt and Bergström 2014].

The measurements of cholesterol content, number of particles or the apoB/apoA-I ratio provide information regarding the level, but do not reflect the functionality, of HDL. With the evolving concept of dysfunctional HDL in which native HDL particles are protective but may become dysfunctional, or even detrimental in conditions such as acute coronary syndrome [Annema and von Eckardstein 2013, Rosenson et al. 2016], measurements of HDL level may be insufficient to understand the role of HDL.

\section{High-density lipoprotein}

\section{HDL proteomics}

Proteomics is the study of protein structure and function. It is derived from the words proteome and omics, where proteome refers to all the proteins expressed by an organism 
while omics is used to describe the analysis of a multitude of different factors simultaneously. As such, the field of lipoproteomics deals with the analysis of protein expression, structure, and function in lipoproteins.

HDL constitutes a heterogeneous population of particles with different protein composition. According to the "HDL Proteome Watch", there are - as of $27^{\text {th }}$ September 2016 - 95 confirmed proteins located on the HDL particles (defined as proteins identified by at least three independent labs in three different publications). All these proteins do not fit on a single particle, instead different subgroups carry subsets of proteins providing a highly diverse group of HDL particles. A selection of these proteins is listed in Table 2.

Table 2. HDL proteins and their respective function

\begin{tabular}{|c|c|c|c|}
\hline Protein & Abbreviation & $\begin{array}{c}\text { MW } \\
(\mathrm{kDa})\end{array}$ & Major function \\
\hline Alpha-1-antitrypsin & $\alpha 1-\mathrm{AT}$ & 47 & Serine protease inhibitor \\
\hline Apolipoprotein A-I & ApoA-I & 31 & Structural protein, LCAT activator \\
\hline Apolipoprotein A-II & ApoA-II & 11 & Structural protein \\
\hline Apolipoprotein C-II & ApoC-II & 11 & Activator of lipoprotein lipase \\
\hline Apolipoprotein C-III & ApoC-III & 11 & Inhibitor of lipoprotein lipase \\
\hline Apolipoprotein $\mathrm{E}$ & ApoE & 36 & Receptor ligand, anti-inflammatory \\
\hline Apolipoprotein F & ApoF & 35 & Inhibitor of CETP \\
\hline Apolipoprotein L-1 & ApoL-1 & 44 & Parasitic defense \\
\hline Apolipoprotein M & ApoM & 21 & $\begin{array}{c}\text { Binding of small hydrophobic } \\
\text { molecules }\end{array}$ \\
\hline $\begin{array}{l}\text { Cholesteryl ester transfer } \\
\text { protein }\end{array}$ & CETP & 55 & $\begin{array}{l}\text { Transfer of lipids between HDL } \\
\text { and apoB-containing lipoproteins }\end{array}$ \\
\hline $\begin{array}{c}\text { Phosphatidylcholine-sterol } \\
\text { acyltransferase }\end{array}$ & LCAT & 50 & $\begin{array}{c}\text { Esterification of cholesterol to } \\
\text { cholesteryl ester }\end{array}$ \\
\hline Phospholipid transfer protein & PLTP & 55 & $\begin{array}{l}\text { Transfer of lipids between HDL } \\
\text { and apoB-containing lipoproteins, } \\
\text { fusion of HDL particles }\end{array}$ \\
\hline Serum amyloid A1/A2 & SAA1/SAA2 & 14 & Acute phase reactants \\
\hline $\begin{array}{c}\text { Serum paraoxonase/- } \\
\text { arylesterase } 1\end{array}$ & PON1 & 40 & Anti-oxidative \\
\hline Transthyretin & TTR & 16 & Transport of thyroid hormones \\
\hline Zinc-alpha-2 glycoprotein & AZGP1 & 34 & Adipokine \\
\hline
\end{tabular}

MW - Molecular weight as defined in Uniprot including pre- and propeptide

The predominant protein in HDL is apoA-I, which is a $31 \mathrm{kDa}$ protein that constitutes approximately $70 \%$ of all protein mass in HDL. Each HDL particle contains 2-5 copies of apoA-I that allow the particles to obtain both the discoidal and the spherical conformations [Huang et al. 2011]. Besides being the structural scaffold for the HDL particles, apoA-I acts as an activator of LCAT, serves as an anti-inflammatory mediator and binds as a ligand to different lipoprotein receptors. 
Some proteins in HDL show a propensity for presence on specific HDL subclasses [Davidson et al. 2009]. ApoE is a $36 \mathrm{kDa}$ protein preferentially located in the larger and less dense HDL2 but that also binds to apoB-containing lipoproteins. The HDL-bound apoE is important for the anti-inflammatory effects of apoA-I and facilitates cholesterol efflux from macrophages [Filou et al. 2016, Matsuura et al. 2006]. Another protein preferentially located in HDL2 is apoC-III, which is an $11 \mathrm{kDa}$ protein that acts as an inhibitor of lipoprotein lipase, and also interferes with lipoprotein binding to hepatic receptors [Gordts et al. 2016]. The HDL fraction only constitutes a minority of the total apoC-III levels where the main bulk is in VLDL. The distribution is complex since smaller proteins such as apoC-III may readily re-distribute between fractions depending on the metabolic context, e.g. in fasting and non-fasting state [Holleboom et al. 2011].

Several proteins have been shown to be preferentially located in the dense HDL3 fraction. Alpha-1-antitrypsin is a $47 \mathrm{kDa}$ serine protease inhibitor that has anti-inflammatory effects and acts as a modulator of the immune system [Ehlers 2014]. ApoL-1 is a $44 \mathrm{kDa}$ protein known to constitute a part of the trypanosomal lysis factor which protects against Trypanosoma parasites, causing trypanosomiasis (sleeping sickness), but also displays effects in apoptosis and autophagic cell death [Vanhamme et al. 2003, Vanhollebacke and Pays 2006, Wan et al. 2008]. The protein is also believed to exert an as yet undefined function in HDL since low levels predict the risk of CVD. Furthermore, genetic variants of apoL-1 increase the risk of CVD [Cubedo et al. 2016, Ito et al. 2014]. ApoM is a member of the lipocalin family and forms a barrel structure with a small hydrophobic binding pocket that has the capacity of binding small lipids. One example is sphingosine-1-phosphate (S1P), which has several functions that increase the protective properties of HDL. ApoM is secreted with its $\mathrm{N}$-terminal signal peptide intact, which is necessary for anchoring the apoM to HDL and prevents it from rapid clearance from plasma. ApoM has been shown to be located in a subpopulation of HDL particles with anti-oxidative properties that stimulate cholesterol efflux [Christoffersen et al. 2006, Christoffersen et al. 2008]. Serum amyloid A1 and A2 (SAA1 and SAA2) are acute phase reactants that display 93\% sequence homology. These proteins increase during inflammation and have been shown to reduce the anti-inflammatory properties of HDL and make them pro-inflammatory, possibly by displacing protective proteins from HDL [Han et al. 2016, Yan et al. 2014]. Serum paraoxonase/arylesterase 1 (PON1) is an anti-oxidative enzyme, expressed mainly in the liver, which in the circulation associates with HDL. It was initially identified as an enzyme with the ability to hydrolyze the organophosphate pesticide metabolite paraoxon. The enzyme has since been shown to carry out other activities including arylesterase and lactonase activities, of which the latter have been proposed to be the native function [Khersonsky and Tawfik 2005]. Low paraoxonase and arylesterase activities have been prospectively linked to the development of CVD [Tang et al. 2012]; however, some studies contradict this [Troughton et al. 2008]. A possible contributing factor to the discrepancy is 
that PON1 level and activity differs in certain conditions such as CVD, indicating that PON1 molecules may be inactivated or less functional [Besler et al. 2011, Furlong et al. 2016]. This activity reduction or inactivation may depend on PON1 being located in an HDL enzyme complex together with myeloperoxidase (MPO), where PON1 partially inhibits MPO and MPO deactivates PON1. MPO is a neutrophil-derived protein that is involved in the respiratory burst. It is usually found at low levels in the circulation but increases in inflammation [Huang et al. 2013].

Other proteins shown to reside on HDL include complement components and acute-phase response proteins including retinol-binding protein 4, fibrinogen and kininogen-1. It has been suggested that HDL could play a major role in regulating these processes [Vaisar et al. 2007].

\section{Protein isoforms}

The complexity of the HDL proteome is further increased by the fact that many proteins are expressed as different isoforms caused by e.g. differential gene expression, mutations or co- and post-translational modifications. These can result in truncations of proteins or substitutions of amino acids that may induce a change in the protein expression, folding, structure, stability, or function. For example, a non-synonymous mutation (leading to amino acid substitutions) in a gene may lead to a mutant protein with altered functionality that may impact the function of other HDL associated proteins or the function of HDL itself.

\section{Genetic factors}

Over the years, a wide variety of mutations, or natural variants, in proteins affecting HDL have been described in humans. For apoA-I, there are more than 50 different mutations described that result in a change of amino acids or truncation of the protein. Some of these are known for leading to decreased HDL-C level due to reduced capability of apoA-I to activate LCAT, leading to reduced cholesterol esterification. These mutations are mainly located in the central region of apoA-I that is believed to be critical for the activation of LCAT. Reduced activation of LCAT may lead to loss of HDL maturation and hypercatabolism of lipid-poor apoA-I, resulting in lowering of the apoA-I and HDL-C levels in the circulation. Mutations occurring in the $\mathrm{N}$-terminal region of the protein, have been shown to increase the risk of amyloidosis leading to the deposition of proteins, or truncated proteins, as insoluble fibrils in different tissues, often with adverse effects on the organ functions. The deposition leads to lower apoA-I in the circulation and thereby a lowering of HDL-C [Sorci-Thomas and Thomas 2002]. Several of the mutations occurring in apoA-I have been shown to increase the risk of CVD in the carriers.

Genetically determined PON1 changes are reported to be associated with differences in both paraoxonase and arylesterase activities. One of the most studied is the substitution of 
glutamine at position 192 for arginine (Q192R). This mutation causes the paraoxonase activity to be several-fold higher for the R-allele compared to the Q-allele, while the arylesterase activity is approximately 10\% lower [Tang et al. 2012]. The Q192R mutation has been associated with CVD, but conflicting results exist. A meta-analysis of 43 studies showed only a small increase in CVD risk with the R-allele, which was not evident in only the five largest studies [Wheeler et al. 2004].

For SR-B1, the major HDL-receptor, several genetic defects have been described in humans. In the extracellular region, a mutation causing the exchange of proline for serine at position 297 (P297S) is associated with increased HDL-C, decreased cholesterol efflux from macrophages, altered platelet function and decreased adrenal steroidogenesis in heterozygote carriers. The carriers showed no association with carotid intima-media thickness, a well-known CVD-marker [Vergeer et al. 2011]. Two additional mutations located in the extracellular region of SR-B1 (S112F and T175A) showed similar increases in HDL-C and apoA-I and no signs of accelerated atherosclerosis. These mutations caused lower binding of HDL to the cells expressing the receptor, as well as lower cholesterol uptake/efflux between HDL and the mutant SR-B1 expressing cells [Brunham et al. 2011, Chadwick and Sahoo 2012]. Another mutation in SR-B1 (P376L) was recently identified. This mutation caused similar increases in HDL-C, located mainly in larger HDL2 particles, as seen in the P297S carriers. There were, however, no apparent effects on platelets or the adrenal glands and no association with the intima-media thickness [Zanoni et al. 2016].

\section{Post-translational modifications}

Post-translational modifications (PTMs) produce a large variety of protein isoforms through different mechanisms. Glycosylation happens in the endoplasmic reticulum or the Golgi apparatus during protein production and involves the enzymatic attachment of oligosaccharides onto amino acids. There are two main groups called $\mathrm{N}$-linked glycosylation, which mainly occurs on the amino acid asparagine, and O-linked glycosylation, which occurs mainly on serine or threonine residues. There is also a nonenzymatic glycosylation called glycation that results from the binding of simple sugars directly to the proteins. This slow, spontaneous reaction happens especially in cases of hyperglycemia, such as in diabetics, and may lead to the generation of pro-inflammatory molecules. Proteins may also be truncated N-terminally or C-terminally during their production in cells, or in the circulation. Furthermore, amino acids can also be directly modified by different reactions including chlorination, deamidation, oxidation and phosphorylation.

Many proteins in HDL have been shown to be expressed in various isoforms dependent on PTMs. ApoA-I displays five different isoforms with similar molecular weight when separated by size and charge. The two isoforms with the highest isoelectric point 
correspond to apoA-I with the six amino acid propeptide still attached, so called pro-apoAI. The major isoform that constitutes approximately $70 \%$ of all apoA-I has a lower isoelectric point due to the removal of the propeptide. The last two isoforms are probably deamidation products of the major isoform resulting in acidic shifts with lower isoelectric points [Contiero et al. 1997, Ghiselli et al. 1985]. ApoA-I also displays two larger isoforms when analyzed by two-dimensional gel electrophoresis (2-DE); one at approximately 35 $\mathrm{kDa}$, which has been proposed to be O-glycosylated, while the larger at approximately 50 $\mathrm{kDa}$ may represent dimerization [Karlsson et al. 2005a]. Furthermore, apoA-I can be nonenzymatically glycated, which is associated with severity of CVD in diabetic patients [Pu et al. 2013]. Finally, specific residues in apoA-I can be modified by oxidation of methionines, nitration/chlorination of tyrosines or modification of lysines with reactive carbonyls [Kontush et al. 2015]. Both tyrosine chlorination and methionine oxidation of apoA-I have also been shown to be associated with CVD status, indicating a possible role in the pathology, or potential use as markers, of the disease [Shao et al. 2014].

ApoC-III can be O-linked glycosylated, wherein the addition of a glycan chain and negatively charged sialic acids in sequence produces several different isoforms [Kontush et al. 2015]. Less common fucosylated isoforms of apoC-III have also been identified [Nicolardi et al. 2013]. ApoM has been shown to be composed of five different isoforms depending on N-linked glycosylation and the addition of sialic acids [Karlsson et al. 2006]. The two very similar SAA1 and SAA2 are expressed in several different isoforms created by C-terminal truncation of one, two or four amino acids [Levels et al. 2011].

Despite the fact that many proteins exists in various isoforms, the consequences of these for the function of HDL particles are often unknown. One exception involves glycosylation in apoC-III. In heterozygous carriers of a mutation in the enzyme GalNAc transferase 2, which mediates the initial steps of O-glycosylation, apoC-III was shown to be less glycosylated. The reduced glycosylation was associated with reduced inhibition of lipoprotein lipase [Holleboom et al. 2011]. The consequence of reduced lipoprotein lipase activity is however debated since another study found no alteration in this capacity for less glycosylated apoC-III [Khetarpal et al. 2016]. Another example with described functional consequences involves methionine oxidations in apoA-I. These oxidations have been described to reduce the capacity of apoA-I to activate LCAT and to interact with ABCA1 as well as reducing the ability to remove oxidized lipids [Shao et al. 2008, Zerrad-Saadi et al. 2009].

In summary, protein isoforms caused by genetic factors or by PTMs are numerous and greatly affect the HDL proteome. Investigations of different isoforms may provide improved knowledge regarding the functionality of HDL. 


\section{HDL functions}

The heterogeneous population of HDL particles has several protective functions against CVD, and the list is still growing as HDLs are shown to participate in a multitude of processes. Many of the functions are dependent on the protein cargo of the particles, but associated lipid components also play important roles.

\section{Reverse cholesterol transport}

The reverse cholesterol transport (RCT), in which cholesterol from peripheral cells is transported back to the liver, has historically been seen as the most important function of HDLs with regard to protection against CVD. This notion is based on the reduction of cholesterol from macrophages, or the pathological derivate foam cells, being protective by reducing the atherosclerotic burden [Davidson and Toth 2007]. The RCT begins with the efflux of cholesterol from cells to HDL particles by interaction with ABCA1 and ABCG1. SR-B1 is another possible contributor to cholesterol loading of HDL. However, in mice models, SR-B1 does not participate in the cholesterol efflux from macrophages [Cuchel et al. 2010, Wang et al. 2007]. In humans, ex vivo studies of monocyte-derived macrophages, from individuals with the functional mutation P297S in SR-B1, showed that cholesterol efflux was diminished [Vergeer et al. 2011], indicating that SR-B1 participates in this process.

The second part of the RCT involves the uptake of HDL-C in the liver by SR-B1-mediated selective lipid uptake or CETP-mediated shuttling of cholesterol to apoB-containing lipoproteins, which are subsequently taken up by LDL receptors in the liver [Tall et al. 2008]. HDL-C has been seen as a marker for cholesterol obtained through RCT from foam cells, thereby illustrating the protective role of HDL. However, the actual contribution of cholesterol from foam cells to the HDL-C in the circulation is most likely negligible, indicating that circulating HDL-C is a poor marker for actual RCT [Lee-Rueckert et al. 2016].

\section{Endothelial wall function and integrity}

HDLs have been described as having the ability to maintain the endothelial cell wall function and integrity through enhancing nitric oxide production. OxLDL depletes endothelial cell membrane caveolae of cholesterol, leading to the subsequent relocation of endothelial nitric oxide synthase (eNOS) away from the caveolae, thereby reducing nitric oxide production. HDL can reduce the eNOS relocation and cholesterol depletion by signaling through the SR-B1 receptor [Uittenbogard et al. 2000]. An important factor for maintaining the endothelial wall is apoM-associated S1P, which interacts with five different G-coupled S1P receptors [Christoffersen et al. 2011]. S1P signaling has been shown to induce nitric oxide production in endothelial cells, thereby causing vasodilation through 
the activation of eNOS, as well as promoting endothelial barrier function [Nofer et al. 2004, Argraves et al. 2008].

\section{Inflammation/oxidative stress}

The anti-inflammatory/anti-oxidative actions of HDL are dependent on many processes mediated by different functional entities. HDL can remove oxidized lipids from oxLDL and thereby reduce their uptake by macrophages in the arterial wall. This process includes the transfer of oxidized phosphatidylcholine, cholesteryl esters, and cholesterol from the surface, but not the core, of the oxLDL. ApoA-I and its methionine residues play an integral part in this process and oxidation of HDL particles has been shown to diminish the transfer of oxidized lipids [Rasmiena et al. 2016]. ApoA-I has further anti-inflammatory functions including reduction of Toll-like receptor 4 signaling, and inhibition of integrin expression in endothelial cells and monocytes [Vuilleumier et al. 2013].

The denser HDL3 fraction has been shown to contribute more to the anti-oxidative capacities of HDL than the larger HDL2 [Kontush et al. 2003]. A plausible mechanism is the association of anti-inflammatory proteins including apoM and PON1. ApoM contributes to the anti-inflammatory activities by its binding of oxidized phospholipids as well as S1P in its hydrophobic pocket. S1P acts on endothelial cells to reduce TNF $\alpha$ induced expression of adhesion molecules on vascular cells, thereby reducing vascular inflammation [Elsøe et al. 2012, Galvani et al. 2015]. Furthermore, HDL signaling through SR-B1 and S1P-receptors converges in the AMPK-signaling pathway, which results in eNOS activation and subsequent inhibition of the expression of the adhesion molecule VCAM-1 [Kimura et al. 2010]. PON1, on the other hand, has different functions that reduce oxidation/inflammation including prevention of LDL oxidation. The mechanism for reducing oxLDL generation is not fully understood but could possibly depend on the hydrolysis of oxidized lipids. This, in turn, reduces the production of inflammatory MCP1 in arterial cells, thereby preventing vascular inflammation. PON1 also acts directly on macrophages and reduces the oxidative stress/inflammation response [Mackness and Mackness 2015].

A recently described anti-inflammatory function of HDL is the suppression of inflammasome activation, a cellular component that participates in the maturation of proinflammatory cytokines IL-1 $\beta$ and IL-18 [Thacker et al. 2016]. Increased inflammasome expression has been found in atherosclerotic lesions, indicating a role in CVD pathogenesis [Paramel Varghese et al. 2016].

\section{Apoptosis}

HDL can act in a cytoprotective manner by inhibiting apoptosis in different cell types, including macrophages and endothelial cells. Protective effects include removal of oxidized lipids, reducing the generation of intracellular reactive oxygen species and the stimulation 
of nitric oxide production. Several components of HDL contribute to these functions including apoA-I, PON1 and S1P [de Souza et al. 2010, Terasaka et al. 2007, Kontush 2014].

\section{Micro-RNA}

A relatively new feature ascribed to HDL is the transport of micro-RNA (miR). These endogenous and small nucleotides work by preventing translation or promoting degradation of mRNA with subsequent effects on target protein expression. They have been described to target different HDL-receptors including ABCA1, ABCG1, and SR-B1 [Ono et al. 2015]. miRs were first shown to be transported and delivered by HDL to recipient cells in 2011, and since then HDL has been demonstrated to deliver miR-223 to endothelial cells in vitro and act in an anti-inflammatory capacity by the down-regulation of ICAM-1 expression in recipient cells [Vickers et al. 2011, Tabet et al. 2014]. The significance of miRs bound to HDL is not clear as it constitutes only a minor fraction of the total plasma miRs, and the efficiency of the transfer to recipient cells has been questioned [Wagner et al. 2013].

In summary, HDL displays a broad range of functions that act protectively against diseases, including CVD. The functions may, however, be altered by external factors such as smoking and diet. Humans are exposed to a wide variety of different chemicals in everyday life where dietary intake constitutes a major route of exposure. Due to industrial activities, some dietary-associated chemicals such as persistent organic pollutants (POPs) are widespread throughout the world and constitute a significant exposure risk for humans.

\section{Persistent organic pollutants}

POPs are a diverse set of chemical compounds defined by the Stockholm Convention that is hosted by the United Nations Environmental Programme. The convention aims at eliminating or reducing the release of these compounds into the environment. There are, as of 2016, 30 different compounds or groups of compounds listed including polychlorinated biphenyls (PCBs), polychlorinated dibenzo-p-dioxins (PCDDs), polychlorinated dibenzofurans (PCDFs), organochlorine pesticides (OCPs) and polybrominated diphenyl ethers (PBDEs). These share the common feature of persistence and accumulation in the fatty tissue in humans and wildlife. Many are known or believed to be detrimental to human health [Stockholm Convention 2016].

PCBs consist of two benzene rings with carbon positions 2-10 substituted by chlorine atoms. This substitution gives rise to 209 variants, known as congeners. Congeners with chlorine-substitutions causing the benzene rings to be coplanar resemble the PCDDs (dioxins) and may, therefore, act in a similar way [Perkins et al. 2016]. 
PCDDs and PCDFs also consist of two benzene rings with chlorine-substitutions, connected by a double- or single-oxygenated ring respectively. There are 75 congeners for PCDD and 135 for PCDF, of which seven PCDDs and ten PCDFs have toxic properties. The most toxic substance is 2,3,7,8-tetrachlorodibenzo-p-dioxin (TCDD) [Dopico and Goméz 2015].

OCPs are a diverse group of chlorinated chemicals used as pesticides. One of the most prominent is dichlorodiphenyltrichloroethane (DDT), and its more persistent metabolite dichlorodiphenyldichloroethylene (DDE). The use of DDT is not banned under the Stockholm Convention, but its use is restricted, and efforts are being made to replace it with less persistent chemicals.

PBDEs are a group of chemicals used as flame retardants and are therefore often called brominated flame retardants. They consist, similarly to PCBs, of two benzene rings, but rather than chlorine substitutions harbor bromine atoms [Stockholm Convention 2016].

\section{Effects of POPs}

POPs have a broad range of ascribed effects. Many of these are related to increased inflammation or disruption of hormone signaling, so-called endocrine disruption. The coplanar PCB congeners and PCDDs interact with the aryl hydrocarbon receptor, known to affect signal transduction of retinoic acid receptors, estrogen receptors, and nuclear factor-kappa B (NF- $x \mathrm{~B})$, contributing to increased generation of reactive oxygen species [Quintana 2013, Perkins et al. 2016].

In vitro studies of human endothelial cells and adipocytes have shown that activation of the aryl hydrocarbon receptor by dioxins or coplanar PCBs increases the expression of genes and miRs involved in inflammation signaling pathways [Felty et al. 2010, Kim et al. 2012, Wahlang et al. 2016]. The non-coplanar PCB congeners do not bind to the aryl hydrocarbon receptor but act through separate mechanisms as endocrine disruptors and inhibitors of gap junction signaling [Hamers et al. 2011].

In vivo studies have shown that feeding rats with a mixture of PCBs induces increased plasma HDL-C [Kato et al. 1989, Oda and Yoshida 1994]. A possible mechanism could be that PCBs bind to the pregnane $\mathrm{X}$ receptor (PXR, also called steroid and xenobiotic receptor). PXR is a nuclear receptor important for the clearance of steroids, drugs and xenobiotic compounds by regulation of metabolic enzymes and inhibition of NF- $x \mathrm{~B}$ [Tabb et al. 2004, Zhou et al. 2006]. Activation of this receptor in rat hepatocytes reduces the expression of ABCA1 and SR-B1 [Sporstøl et al. 2005], which may explain the increased levels of HDL-C found when feeding rats PCBs. However, treatment with PXR agonist in a transgenic mouse model expressing human apoE and CETP, designed to mimic human lipoprotein metabolism, decreased HDL-C indicating a shuttling of cholesterol to apoB- 
containing lipoproteins [de Haan et al. 2009]. There also appears to be a species difference since PCBs can act as both agonists and antagonists, depending on the concentration, in cells expressing human PXR but not the rat or mouse PXR [Al-Salman and Plant 2012, Tabb et al. 2004].

The major OCP in the human circulation is DDE, and high levels have been shown to induce pro-inflammatory molecules in peripheral blood monocytes in vitro [CárdenasGonzález et al. 2013]. Another OCP, trans-nonachlor, has been demonstrated to promote the production of intracellular reactive oxygen species by increasing the activity of NADPH oxidase in human monocytes. Interestingly, DDE did not cause a similar effect [Mangum et al. 2015], indicating that these compounds could have different target cells and/or modes of action.

POPs are slowly metabolized in the human body, whereas PCBs may be hydroxylated by cytochrome P-450 enzymes. There are 837 possible mono-hydroxy PCB metabolites, and each congener may be further oxidized producing multi-hydroxy metabolites that may promote oxidative stress. The hydroxyl metabolites of PCBs are found in significant levels in humans, and some metabolites are present in similar concentrations as less common PCB congeners [Fängström et al. 2002, Grimm et al. 2015]. Hydroxylation of PCBs, PCDD/Fs, and PBDEs causes metabolites to become more estrogenic and disrupt thyroid hormone signaling by binding to transthyretin (TTR) [Bergman et al. 1994, Lans et al. 1993, Meerts et al. 2000]. PCBs may also be metabolized to methyl sulfones shown to be present in low concentrations in the circulation but selectively accumulated in the liver [Grimm et al. 2015].

One concern regarding POP exposure is that the different compounds can exert effects wherein two agents give an additive response relative to the two compounds separately, a so-called synergistic effect. Since humans are exposed to a variety of different POPs, with the added complexity of metabolites, synergistic effects may constitute a major exposure factor for POPs. A synergistic effect has been demonstrated by feeding rats a mixture of 12 PCBs, two dioxins, and four dibenzofurans during a 4-day period, resulting in decreased level of the thyroid hormone T4 [Crofton et al. 2005]. Furthermore, co-exposure of TCDD and a PCB mixture to atherosclerosis-prone apoE knock-out mice showed that these compounds acted in a synergistic manner to increase atherosclerosis, measured as increased arterial plaques, accompanied by increased total cholesterol, LDL-C and the inflammatory marker MCP-1 [Shan et al. 2014].

\section{POPs and cardiovascular disease}

Due to the pro-inflammatory properties of POPs and the strong contribution of inflammation to CVD, an association between these factors is likely. As such, there is an 
increasing volume of literature showing an association between POPs and CVD [Lind and Lind 2012]. Epidemiological studies have shown that hospitalization rates for CVD are increased among individuals living in areas with known POP contaminations [Sergeev and Carpenter 2010]. An investigation using the National Health And Nutritional Examination Survey (NHANES) cohort has shown that there is an association between POP and CVD in women only. However, a later study of the same cohort showed an association between PCB and CVD mortality in both genders [Ha et al. 2007, Kim et al. 2015]. Studies from the Prospective Investigation of the Vasculature in Uppsala Seniors (PIVUS) cohort have shown that several PCB congeners are associated with atherosclerotic plaques. Furthermore, the sum of PCBs was associated with increased oxLDL but also, paradoxically, decreased oxidative markers GSSG and GSH/GSSG [Lind et al. 2012, Kumar et al. 2014]. A prospective study using the same cohort has shown that POPs were prospectively associated with lipid values such as total cholesterol and LDL-C [Penell et al. 2014].

Highly chlorinated PCB congeners are known to be more lipophilic and persistent than less chlorinated congeners. The plasma levels of highly chlorinated congeners have been shown to be positively associated with LDL-C, something not seen for less chlorinated congeners [Aminov et al. 2013]. Plasma levels have also been linked to an echolucent intima-media complex that is indicative of lipid enrichment in the vascular wall and a possible predictor for future CVD [Lind et al. 2012, Wohlin et al. 2009]. These studies indicate that highly chlorinated PCB congeners may act differently to less chlorinated congeners, and might promote CVD through separate mechanisms.

With a growing body of evidence suggesting that POPs are associated with CVD, it is essential to investigate potential mechanisms mediating the effects of POPs. HDL represents an important protective factor against CVD through its multitude of functions and constitutes a possible transport mechanism for POPs in the circulation due to the lipophilic nature of these compounds. There is, however, little or no information regarding the HDL system in relation to POPs and whether these pro-inflammatory compounds may interact with HDL and influence the protective functions. 


\section{Aims}

HDL is a multifaceted population of particles intricately involved in lipid transport and protection against CVD. Its protein composition is subject to change due to individual gene expression profiles, but also to external factors such as environmental stressors. The overall aim of this thesis was to investigate the HDL proteome and how genetic factors and pollutants affect the composition and function of the particles.

Specific aims of the papers:

- To identify the apoA-I L202P and K131del variants in HDL, and investigate differences in the HDL proteome between heterozygous carriers and family controls (Paper I)

- To investigate alterations in HDL and LDL/VLDL in heterozygous carriers of the P297S mutation in SR-B1 compared to family controls (Paper II)

- To quantify the level of POPs transported in lipoproteins from individuals living in a contaminated community and explore whether this is associated with CVD or cancer (Paper III)

- To analyze the HDL proteome and function in relation to levels of POPs in individuals living in a contaminated community (Paper IV) 


\section{Methods}

\section{Study design}

Papers I and II are investigations of heterozygote carriers with mutations in two essential proteins (apoA-I and SR-B1) in the lipoprotein metabolism that cause altered levels of HDL-C. These mutations were found after screening of lipid values, where individuals with extreme HDL-C values (top and bottom 5\%) were invited for further testing and genotyping of genes known for participating in the lipoprotein metabolism. This resulted in the identification of the mutations. Subsequently, family members of the index patients were also invited to examine the hereditary component of the abnormal HDL-C levels. The apoA-I mutations in Paper I caused decreased apoA-I and HDL-C levels [Hovingh et al. 2004, Tilly-Kiesi et al. 1995] while the SR-B1 mutation in Paper II is associated with increased levels of HDL-C and reduced cholesterol efflux from macrophages [Vergeer et al. 2011]. Lipoproteins were isolated and separated with a gel-based proteomic method and several functional tests of HDL were performed.

Paper III and IV are based on investigations of a population living in a POP-contaminated area. This community has an industrial history with a brass factory from which POPcontaminated oil was released into the local river continuously for many years up until the 1980 's. In addition, there was a large accidental spill at the beginning of 1970's that led to the widespread death of fish in the local waters surrounding the area. As part of environmental health surveillance, a study was initiated to investigate possible health effects from living in the area and consuming local wildlife, vegetables, fruit, and berries. Study participants answered a detailed questionnaire regarding health, diet, lifestyle factors as well as occupational history, followed by collection of blood samples [Helmfrid et al. 2012]. As a sub-study, lipoproteins were isolated and investigated regarding their POP constituents. Analyses were further expanded also to include the proteomic contents, analyzed by a gelfree proteomic approach, as well some functional measures to elucidate the possible impact of POPs on HDL.

\section{Ultracentrifugation}

Ultracentrifugation of lipoproteins was first described in the 1940's and the densities of VLDL, LDL and HDL were defined in 1955 [Havel et al. 1955]. Since then, the method has evolved with respect to chemicals used for creating a density gradient and centrifugation times. A relative fast and efficient method has been developed in which lipoproteins are isolated with a two-step discontinuous isolation using potassium bromide $(\mathrm{KBr})$ as the gradient [Karlsson et al. 2005a, Karlsson et al. 2005b]. The method is performed by mixing plasma with sucrose and EDTA to prevent coagulation, followed by addition of a fixed amount of $\mathrm{KBr}$ to increase the density in the solution. The solution is 
transferred to specific ultracentrifugation tubes and a KBr solution with pre-set density is gently added on top of the plasma. Ultracentrifugation at $290000 \mathrm{G}$ for $4 \mathrm{~h}$ causes lipoproteins to float upwards towards their respective density. By piercing through the tubes with a syringe, the lipoprotein fractions can be extracted from a defined density. Extracted lipoprotein fractions are further purified by a second step in which they are separately mixed with high density $\mathrm{KBr}$ solution. The resulting solution is subjected to another round of ultracentrifugation for $2 \mathrm{~h}$ that helps remove contaminating albumin and immunoglobulins from the lipoprotein fraction of interest. The top portion of the tubes is collected as described previously. Ultracentrifugation was used in Papers I-IV.

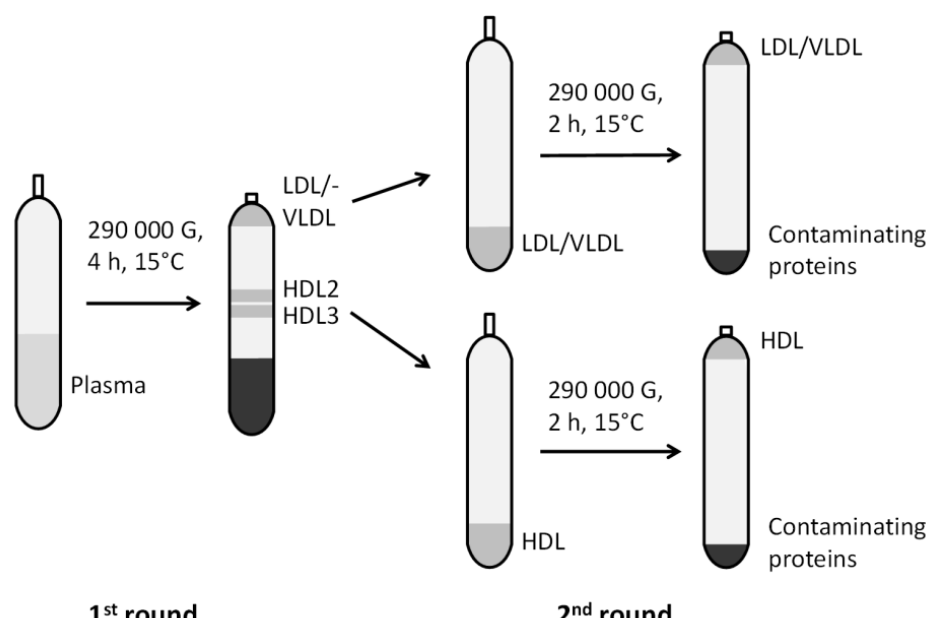

Figure 1. Lipoprotein separation using ultracentrifugation. Lipoproteins are allowed to float to their density range before being extracted. By employing a second round of ultracentrifugation, eventual contaminating proteins may be removed.

\section{Two-dimensional gel electrophoresis}

2-DE is a well-established method used for a variety of proteomic analyses [Görg et al. 2009]. It is a way to separate proteins in two dimensions according to their isoelectric points (the point on a pH-scale where the net charge of all constituent amino acids is zero) as well as their size (molecular weight). The method allows the separation of isoforms that is not accomplished by separating by size or charge alone. The first step of isoelectric focusing is performed by allowing a solution, containing denatured proteins, to rehydrate pre-made gel strips containing a $\mathrm{pH}$-gradient. By applying an electric field, proteins move toward their isoelectric point [Görg et al. 2009]. When proteins have been isoelectrically focused, the strip is transferred to polyacrylamide gel for sodium dodecyl sulfate polyacrylamide electrophoresis. This gel allows for the separation of denatured, linearized proteins according to their size since smaller proteins migrate faster through the polyacrylamide 
mesh compared to larger proteins when subjected to an electric field. After separation, the proteins are fixed in a solution containing methanol and acetic acid, preventing the proteins from diffusing in the gel. Subsequently, the proteins are stained allowing visualization of the proteins. There exist different staining methods including silver staining, which is a relatively sensitive stain able to detect 1-10 ng of protein [Shevchenko et al. 1996]. Another type is fluorescent stains that show a broader linear range as compared to silver [Lopez et al. 2000]. After staining, the gels are digitalized using a camera. These images are then used for quantification, based on the optical density or fluorescence intensity. 2-DE was applied in Paper I and II.

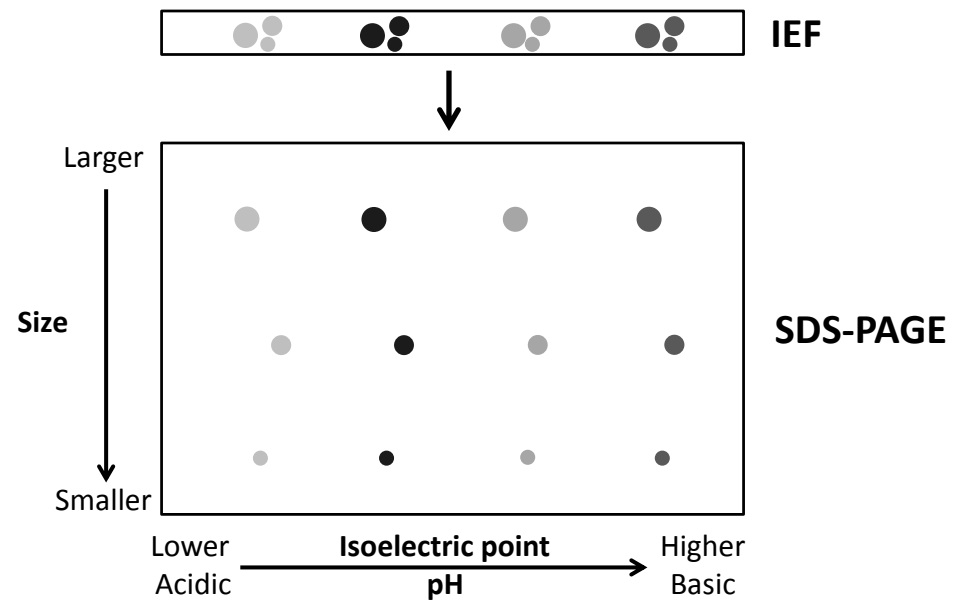

Figure 2. 2-DE separation of proteins. Proteins are first separated according to their isoelectric point where their net charge is zero (isoelectric focusing - IEF). The proteins are then transferred to a second polyacrylamide gel that separates the proteins according to their size (SDS-PAGE). Following staining, the relative amount of different proteins and isoforms can be determined.

\section{Matrix-assisted laser desorption/ionization time-of-flight mass spectrometry}

Matrix-assisted laser desorption/ionization time-of-flight mass spectrometry (MALDITOF MS) utilizes a matrix to ionize compounds such as peptides. The method can be used to identify proteins downstream of 2-DE. The isolated protein is physically removed from the gel and de-stained, in order to negate interference from the stain with mass spectrometry. The protein is extracted from the gel by digestion with an endoproteinase or chemical that cleaves the protein at specific amino acids. Most widely used is the endoproteinase trypsin, a serine protease that cleaves proteins at the carboxyl side of arginine or lysine except when followed by a proline. A chemical that can be used instead of enzymes is cyanogen bromide that cleaves $\mathrm{C}$-terminally of methionine. 
The cleavage results in peptides that are then extracted from the gel, dried by vacuum centrifugation and reconstituted in water containing trifluoroacetic acid to enhance peptide ionization. Peptides are then mixed with a matrix, commonly 2,5-dihydroxybenzoic acid or $\alpha$-cyano-4-hydroxycinnamic acid. The former has been shown to perform better in the identification of low-abundant proteins stained with silver from 2-D gels [Ghafouri et al. 2007]. The matrix-peptide mix is placed on a target plate and allowed to dry, causing crystallization. The MALDI functions by a laser targeted to the crystals, where the energy causes the peptides to evaporate, and an electric field accelerates the ions away from the plate. The ions travel through a flight tube consisting of an electrical field in vacuum. Since no factors other than mass affects the peptides in the vacuum, the time it takes for the ions to fly from the laser pulse until they hit the detector is used to calculate the mass-to-charge ratio $(\mathrm{m} / \mathrm{z}$ ) corresponding to the size of the peptide [Hortin 2006]. A list of $\mathrm{m} / \mathrm{z}$ is then subjected to a database search for determination of which peptides are in the sample and thereby what protein they originate from, a process known as peptide mass fingerprinting. Several peptides can, however, have similar $\mathrm{m} / \mathrm{z}$, so it is the combination of masses that determine which protein that is most probable. MALDI-TOF MS was used in Paper I and II.

\section{Electrospray ionization quadrupole time-of-flight mass spectrometry}

Electrospray ionization quadrupole time-of-flight mass spectrometry (ESI-Q-TOF MS) is a hybrid instrument in which peptides are ionized with ESI, and quadrupoles are used for selection and fragmentation of ions with collision-induced dissociation (CID). A solution containing peptides, obtained in the same way as for MALDI-TOF MS, are dried by vacuum centrifugation, reconstituted in $0.1 \%$ formic acid and loaded into an offline silver electrospray capillary. Peptides are ionized by ESI where a voltage is applied between the tip of the capillary and the mass spectrometer, leading to a spray of the peptide solution. The spray causes the initial droplets containing charged ions to break apart in the air due to solvent evaporation. Charged ions are ejected from the droplets and transfer to the MS system [Ho et al. 2003]. By selection and fragmentation of specific peptide masses, the sequence of amino acids can be determined. ESI-Q-TOF MS was used in Paper II to identify the mutant peptides. 

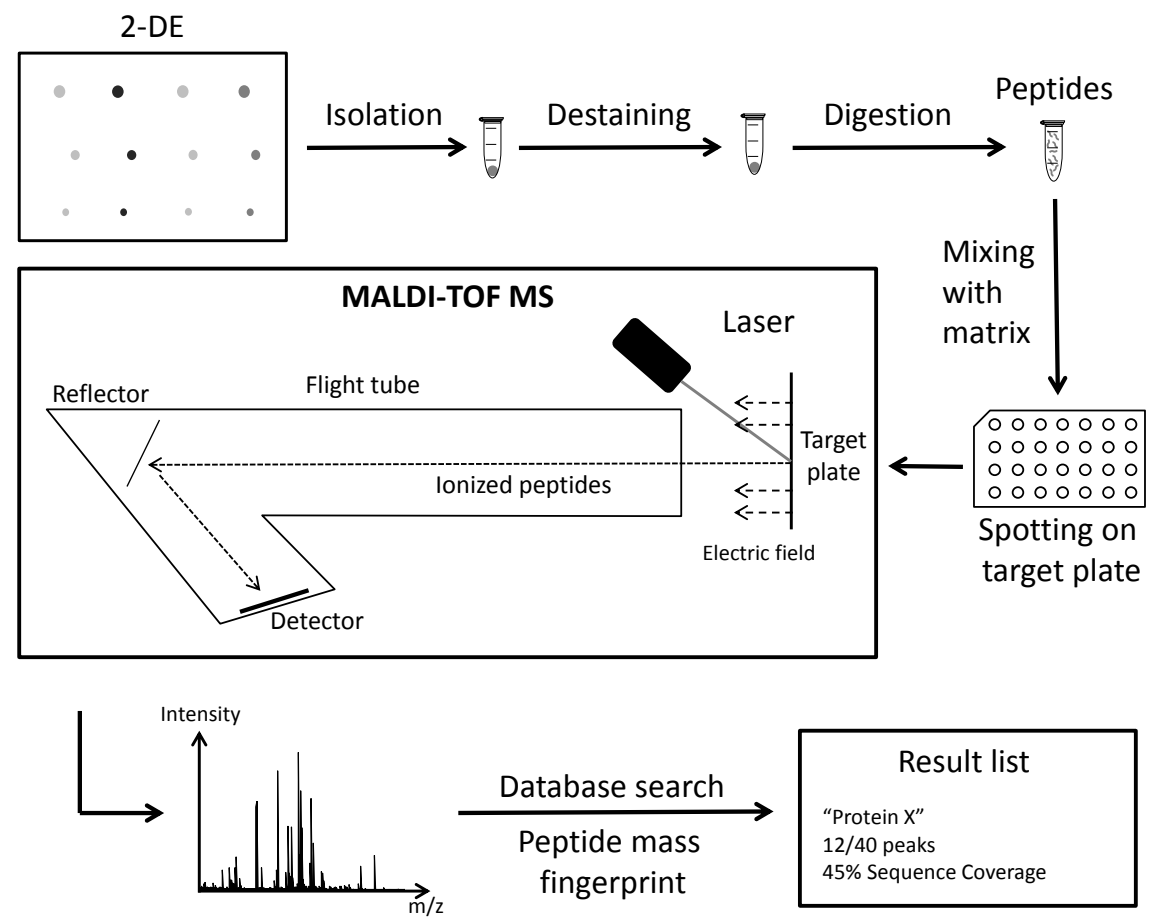

Figure 3. MALDI-TOF MS peptide mass fingerprinting after 2-DE. Spots representing protein or protein isoforms are physically cut out of the gel and subjected to de-staining before digestion. Resulting peptides are mixed with matrix and spotted on a target plate. In the MALDI-TOF MS, a laser evaporates/ionizes the peptides and the transfer time through the flight tube to the detector is measured. The time from the laser pulse until the ion hit the detector is translated to the size of the peptides, expressed as a mass-to-charge ratio, while the electric signal generated by the peptides corresponds to the intensity. The resulting spectrum is then subjected to a database search against the genome of interest generating a peptide mass fingerprint with the identification of the protein.

\section{Nano-liquid chromatography tandem mass spectrometry}

Nano-liquid chromatography tandem mass spectrometry (nLC-MS/MS) represents a gelfree proteomics method that both separates and identifies the proteins. Isolated lipoproteins from ultracentrifugation are desalted and lyophilized before being reconstituted in a buffer. Proteins are reduced with dithiothreitol and alkylated by the addition of iodoacetamide to prevent cysteine from reforming disulfide bridges. A volume with a specific amount of proteins is mixed with endoproteinase, most often trypsin, to generate peptides. These are lyophilized and reconstituted in water containing $0.1 \%$ formic acid, which works similar to trifluoroacetic acid, to facilitate ionization. The sample is loaded into a C18 analytical column, and the peptides are separated according to size and hydrophobicity by using an increasing concentration of the organic solvent acetonitrile. 
The peptides are ionized by ESI and delivered to the mass spectrometer. One type of mass spectrometer that was used in Paper II and IV is an LTQ-Orbitrap Velos Pro (Thermo Fisher). It is a hybrid instrument with two ion traps/detectors; a linear ion trap and an Orbitrap. It works by a pre-scan of the peptides in the Orbitrap, which has higher resolution, followed by fragmentation of the most intense ions with CID in the faster linear ion trap. The use of both these components represents a compromise in achieving high resolution during pre-scans, and speed during fragmentations. nLC-MS/MS was employed in Paper I, II and IV.

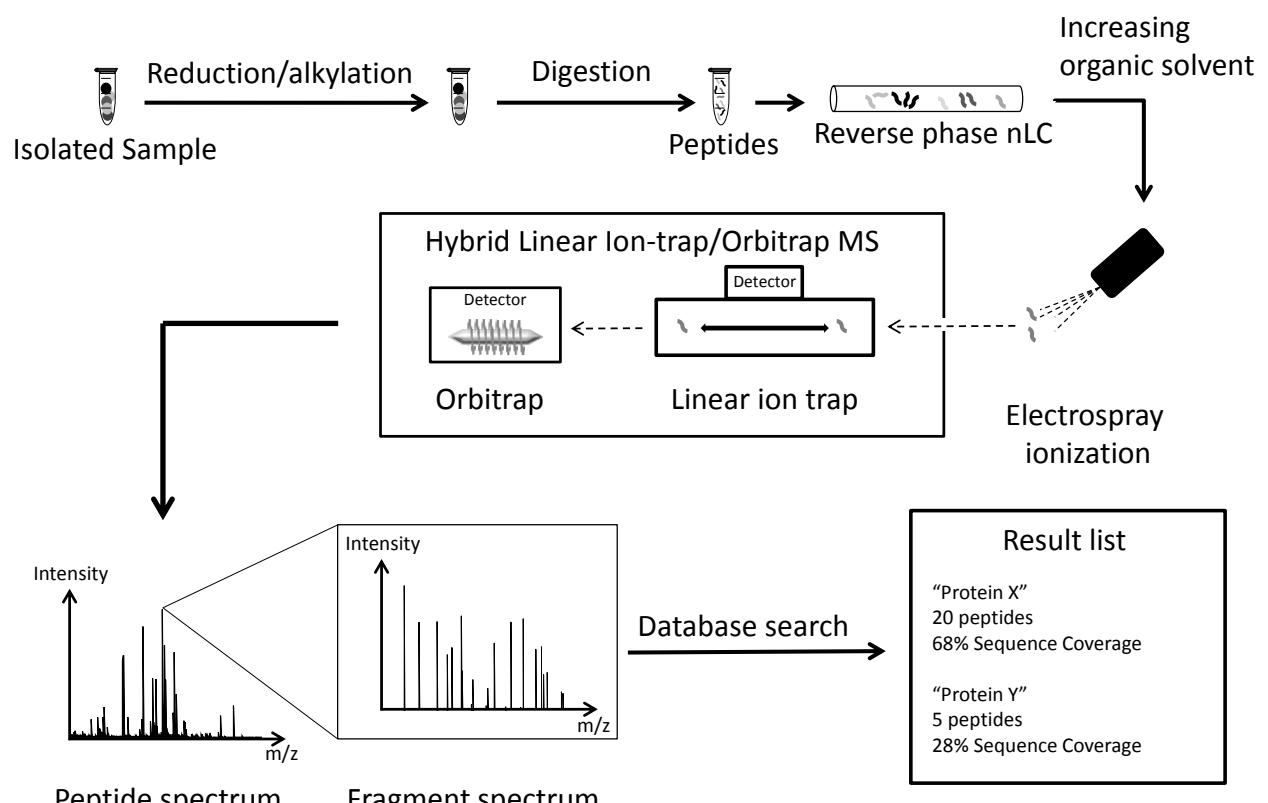

Figure 4. nLC-MS/MS principle. Proteins are reduced and alkylated before digestion. Resulting peptides are separated using nano-liquid reverse phase liquid chromatography and ionized using electrospray ionization that delivers the peptides to the mass spectrometer. Spectra is obtained by a data-dependent acquisition method, in which the Orbitrap scans a certain mass range and the most intense peptides are selected for fragmentation using CID in the linear ion trap. The resulting spectra are searched against a database to provide identification of the proteins.

\section{Data processing after nLC-MS/MS}

The nLC-MS/MS produce a large volume of information in the form of chromatograms and spectra. The spectra may be used to search against a database of interest such as the human proteome. With spectra from both the full-scans, performed by the Orbitrap, and the fragmentation spectra from the linear ion trap, sequencing of peptides and identification of proteins is possible. The data processing also allows for the identification 
of PTMs, such as methionine oxidations, since this involves an addition of mass on the peptides. However, some PTMs such as phosphorylations and glycosylations may benefit from using means other than CID for fragmentation such as electron-transfer dissociation.

Quantification of peptides and proteins may be performed using both label-based and label-free approaches. Label-based methodologies most often utilize stable isotopes to label samples before analysis. This provides some advantages, including the ability to label samples with different tags and analyzing them simultaneously (multiplexing), but it also provides an increased reproducibility compared to the label-free methods. It does, however, introduce additional sample preparation steps before nLC-MS/MS analysis and sometimes a need for more specialized MS methodologies. Label-free quantification, on the other hand, allows high-throughput analysis of samples and has a higher dynamic range compared to label-based quantification. The label-free quantification can be performed by either counting the number of times a fragment-ion, corresponding to a peptide, is found (spectral counting) on MS/MS level or by measuring the intensity of the precursor ions corresponding to intact peptides on the MS level [Megger et al. 2013].

Different software packages exist that allow label-free quantification. MaxQuant is freeware developed for high-resolution MS instrumentation such as Orbitraps [Cox and Mann 2008]. It contains various features including a software lock-mass that recalibrates the spectra dependent upon a first search to increase the mass accuracy [Cox et al. 2011]. The software utilizes label-free quantification based on the peptide intensities (MS-level) and it extracts the intensity data for all peptides corresponding to each protein, compares different samples and uses this to construct an intensity profile between the samples for each protein. This method provides intensities that function as proxy for absolute protein abundance, shown to be superior to spectral counting or summation of the total intensity of the peptides [Cox et al. 2014].

\section{Analysis of persistent organic pollutants}

Analysis of persistent organic pollutants (POPs) was performed according to a previously developed method [Salihovic et al. 2012]. Isolated lipoprotein fractions are mixed with formic acid and sonicated to denature the proteins followed by addition of an internal standard constituting of ${ }^{13} \mathrm{C}$-marked POPs to each sample. Samples are subsequently filtered through solid-phase extraction columns to remove proteins followed by lipid removal with multilayered acidified silica columns. A ${ }^{13} \mathrm{C}$-labeled recovery standard is added to the samples, which is then analyzed by a high-resolution gas chromatography/high-resolution mass spectrometer (HRGC/HRMS). Concentrations of 14 PCB congeners (\#74, \#99, \#105, \#118, \#138, \#153, \#156, \#157, \#170, \#180, \#189, \#194, \#206 and \#209), 1 dioxin (octachlorodibenzo-p-dioxin, OCDD), 4 OCPs (hexachlorobenzene, DDE, cis-chlordane and trans-nonachlor) and 1 brominated flame 
retardant (bromodiphenyl ether \#47) are analyzed using selective ion mode. Quantification is done with an isotope dilution method with ${ }^{13} \mathrm{C}$-labeled standards, and sample limit of detection is determined as the mean of all blank samples plus three times the standard deviation. HRGC/HRMS was used in Paper III.

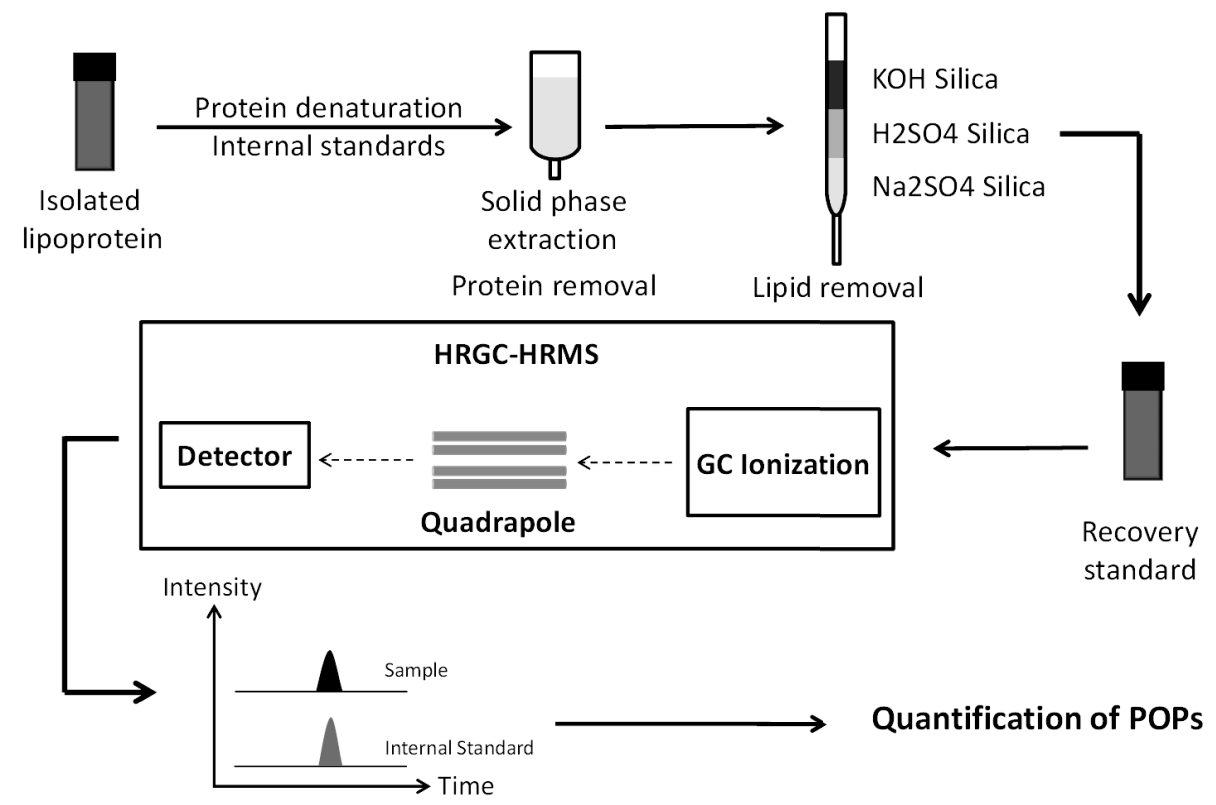

Figure 5. Flowchart of POP analysis. Isolated lipoproteins are denatured, and internal standards with ${ }^{13} \mathrm{C}$-marked POPs are added. Proteins are removed using solid-phase extraction and lipids are removed with a multilayered silica column. A recovery standard is added, and POPs are ionized using high-resolution gas chromatography and analyzed with a selective ion method. Quantification is performed by an isotope dilution method against ${ }^{13} \mathrm{C}$-standards.

\section{Paraoxonase 1 activity analysis}

Traditionally the organophosphate paraoxon has been used to measure the activity of PON1. Since paraoxon is a neurotoxic compound with acute detrimental effects on human health, methods utilizing other non-toxic proxy compounds such as phenyl acetate and lactones have been developed [Khersonsky and Tawfik 2005, Richter et al. 2008]. Phenylacetate is an ester, which is hydrolyzed to its components phenol and acetate by the activity of PON1. Phenol can be directly measured at $270 \mathrm{~nm}$ using a spectrophotometer. The method is performed by diluting plasma in a salt buffer containing $\mathrm{Mg}^{+2}$, which is needed by the enzyme to be functional. Samples are mixed with phenyl acetate solution and the increase in phenol, resulting from hydrolysis by PON1, is measured during the initial, linear-phase minutes. The increase in absorbance is then mathematically converted 
to enzyme activity by using the molar extinction coefficient for phenol, resulting in the activity expressed as $\mu \mathrm{mol} / \mathrm{min} / \mathrm{mL}(\mathrm{U} / \mathrm{mL})$. PON1 activity assay was utilized in Paper II and III.

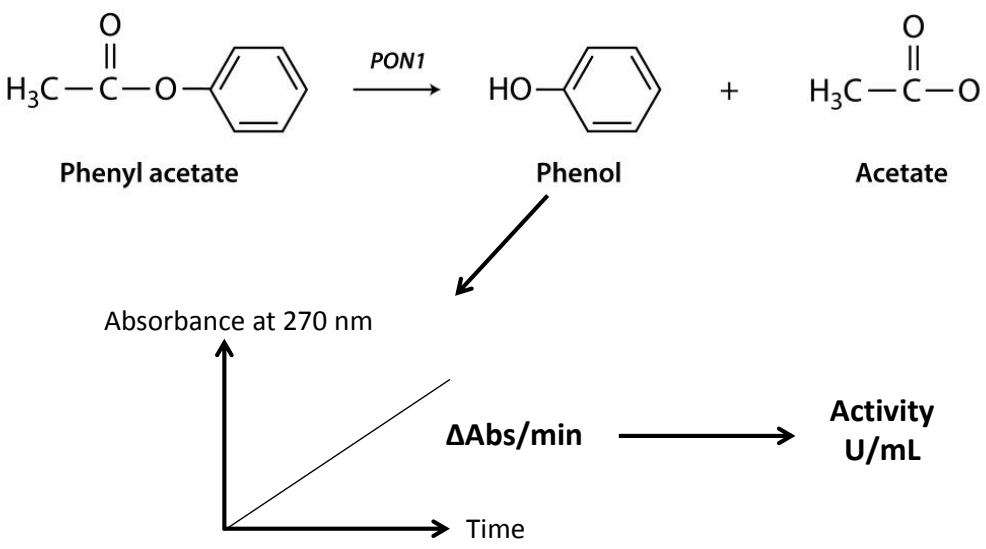

Figure 6. The principle for PON1 arylesterase measurements. Human plasma is mixed with phenyl acetate. By the action of PON1, phenyl acetate is hydrolyzed to acetate and phenol, of which the latter can be measured at $270 \mathrm{~nm}$ by a kinetic method. The resulting absorbance per time unit is transformed into the activity expressed as enzyme unit $(\mu \mathrm{mol} / \mathrm{min}$ ) per volume, $\mathrm{U} / \mathrm{mL}$.

\section{HDL oxidant index assay}

2,7-dichlorofluorescin (DCFH) is a chemical initially used to measure the amount of hydrogen peroxide in solutions, but was later adopted to measure the oxidative burst from neutrophils [Bass et al. 1983] and subsequently adopted as a measure of the ability of HDL to prevent the formation or inactivation of oxidized phospholipids from apoB-lipoproteins [Navab et al. 2001]. The method utilizes HDL obtained by depletion of apoB-containing lipoproteins from plasma. HDL is placed in a well and mixed with a specified amount of apoB-lipoproteins. The content of oxidized lipids in the apoB-containing lipoprotein facilitates the transformation of added DCFH to fluorescent 2,7-dichlorofluorescein (DCF). Normal HDL reduces this reaction with less DCF produced, but since HDL itself may become pro-inflammatory/pro-oxidative in certain diseases [Alwaili et al. 2012], it may also participate in increasing the fluorescence in the DCF assay. As such, fluorescence obtained with mixed HDL/apoB-lipoproteins is compared to only apoB-lipoproteins, in order to investigate the capacity of HDL to act anti-oxidative or pro-oxidative. This is called HDL oxidant index (HOI), and values $<1$ indicate that HDL is functional and antioxidative while values $>1$ demonstrate that HDL is dysfunctional and pro-oxidative. This method has been used to show that, compared to healthy controls, HDL from acute coronary syndrome patients had a decreased ability to inhibit oxidation from apoB- 
containing lipoproteins, while no such effect was seen in patients with stable coronary artery disease [Patel et al. 2011]. A reduced anti-oxidative behavior of HDL was also shown to be a predictor of mortality in critically ill patients attending an intensive care unit with different diseases [Schrutka et al. 2016]. The assay has some limitations since DCF has short shelf life, is sensitive for metal chelators, and that the assay is disturbed by hemolysis [Hafiane et al. 2015]. The HDL oxidant assay was used in Paper II and IV.

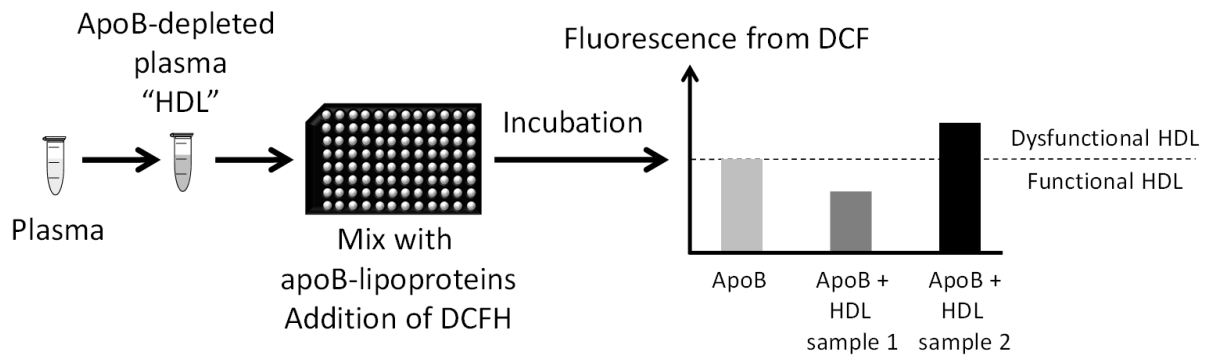

Figure 7. Analysis of HDL oxidant index using the DCF assay. Plasma is depleted of apoBcontaining lipoproteins. Samples are mixed with apoB-lipoproteins and incubated with DCFH. The oxidation product DCF can be measured by fluorescence. The HDL oxidant index is calculated by dividing the fluorescence of the sample with fluorescence of apoB-lipoproteins.

\section{Cholesterol efflux capacity assay}

The cholesterol efflux capacity (CEC) assay is a measure of the ability of HDL to accept labeled cholesterol in vitro as a measurement of HDL functionality. CEC has been shown to be associated with reduced intima-media thickness indicating that it promotes the removal of cholesterol from arterial wall macrophages [Khera et al. 2011]. Prospective studies have shown that CEC is a predictor for CVD, independent of HDL-C [Rohatgi et al. 2014, Saleheen et al. 2015, Zhang et al. 2016]. There is, however, a study showing that CEC was inversely associated with prevalent CVD, but positively associated with incident CVD (in contrast to the other studies) [Li et al. 2013]. CEC has been shown to be affected by inflammation; endotoxin injected in healthy male volunteers reduced CEC while SAA1 and SAA2 in HDL increased. Furthermore, in vitro incubation of HDL with recombinant SAA1 also reduced the CEC [Vaisar et al. 2015].

The assay is performed with macrophage cell lines, where common variants are the murine J774 and RAW 264. The cells are plated and cultured in wells before being loaded with labeled cholesterol. The labeling is commonly accomplished using radiolabeled ${ }^{3} \mathrm{H}$ or ${ }^{14} \mathrm{C}$ cholesterol [Khera et al. 2011, Zhang et al. 2016] but a method using fluorescence-labeled cholesterol has been described [Rohatgi et al. 2014]. ApoB-depleted plasma is added to the 
cells and incubated to allow uptake of cholesterol to HDL/apoA-I in the media. Measurements of cholesterol, by liquid scintillation or fluorescence intensity, in the supernatant and the remaining cells provide a ratio of cholesterol efflux expressed as percentage of total added cholesterol. CEC assay was used in Paper II.

Addition of labeled cholesterol

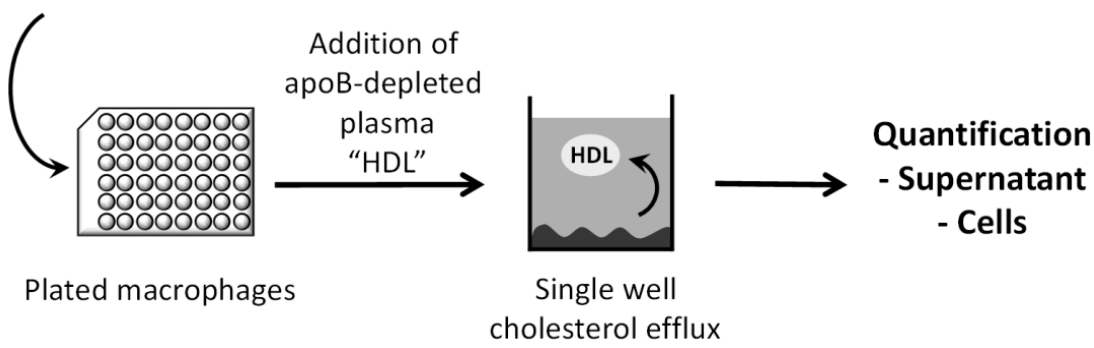

Figure 8. Cholesterol efflux assay. Macrophages are placed in wells and radio- or fluorescencelabeled cholesterol is added. ApoB-depleted HDL is added in the media followed by incubation. The levels of cholesterol are subsequently measured in the supernatant and the cells by liquid scintillation or fluorescence intensity.

\section{Multivariate Statistical analyses}

With the emergence of omics data usually involving many variables and a lower number of subjects, statistical methods that can deal with the increased risk of false positives are needed. Multiple corrections using Bonferroni or Benjamini-Hochberg can address these issues but leads to a significant loss of statistical power. Dimensional-reducing multivariate methods that are not based on set cutoffs such as a p-value may complement univariate methods in omics research [Wheelock and Wheelock 2013].

\section{Principal Component Analysis}

Principal component analysis (PCA) is an unsupervised dimensional-reducing method in which complex datasets are investigated to find underlying structures not apparent to the eye or by univariate statistics. The method investigates the relationship between all variables to find the best explanation for underlying variance in the material. The best fit will represent the first principal component. After this, additional principal components that are orthogonal to the previous one(s) are added sequentially. The resulting data can then be plotted as either the scores of the principal components that explain the samples' clustering, or as the loadings explaining the variables clustering [Checa et al. 2015, Marengo and Robotti 2014]. PCA was used in paper III and IV. 


\section{Partial Least Square}

Partial least squares (PLS) analysis attempts to explain one or more dependent variable(s) $(\mathrm{Y})$ with a set of predictors $(\mathrm{X})$, using a small number of factors that explains the maximum covariance between $\mathrm{Y}$ and $\mathrm{X}$. The relationship between $\mathrm{Y}$ and $\mathrm{X}$ is shown as loading weights, W [Marengo and Robotti 2014]. The X variables can be important for explaining the $\mathrm{Y}$ variable(s) but also the modeling of $\mathrm{X}$. The combined impact is summarized in variable importance in projection (VIP), which is the sum of squares of the PLS weights W. VIP values may be used as a selection criterion to find variables with high importance in the model and thereby allow identification of the variables best explaining the relation between X and Y [Checa et al. 2015, Wold et al. 2001]. PLS was used in Paper II and IV. 


\section{Results and Discussion}

\section{HDL in mutations causing altered HDL-C (Papers I and II)}

In Paper I, a detailed study of two mutations in apoA-I was conducted to investigate how this influences HDL-C and the HDL proteome. Heterozygote carriers for the apoA-I mutations L202P and K131del showed reduced levels of HDL-C compared to their respective controls, in agreement with earlier studies of these mutations [Tilly-Kiesi et al. 1995, Hovingh et al. 2004]. In the study initially identifying L202P, this was believed to be attributed to the fact that mutation was not expressed, with reduced apoA-I and HDL-C as a result. We did, however, detect the mutant protein by isolating HDL with ultracentrifugation, separation of proteins with 2-DE and identification using MS. The mutation causes no visible change in 2-D gels since the exchange of leucine for proline causes no appreciable charge or size shift. Therefore, the identification relied on the MS analyses and a key step was the use of an alternative cleavage strategy. Thus, apoA-I was extracted from the 2-D gels and digested with endoproteinase Glu-C which is unaffected by the presence of proline, contrary to the originally used trypsin. Mutant peptides were found in all five identified isoforms of apoA-I among the heterozygotes. In contrast to L202P, the K131del mutation was readily detectable with 2-DE as the loss of a lysine causes an acidic charge shift in the 2-D gels for all isoforms of apoA-I, generating one additional visible isoform. Also in this case the use of Glu-C was to be preferred above trypsin, since the latter cleaves at the carboxyl side of lysine residues making it unsuitable for detection of the lysine loss. The most acidic isoform of apoA-I contained almost exclusively mutant peptide as found by MS, while the ratio of mutant/wild-type peptide decreased with increasing isoelectric point.

The HDL proteome was investigated by relative quantification of the 2-DE staining. The L202P heterozygotes showed significantly reduced levels of protective apoE in HDL and increased levels of the adipokine zinc-alpha-2-glycoprotein, as compared to controls, possibly indicating a population of particles with detrimental properties. Indeed, HDL from L202P heterozygotes has been shown to have reduced anti-inflammatory capacity and cholesterol efflux [Daniil et al. 2011, Holleboom et al. 2013]. The K131del heterozygotes, on the other hand, showed increased levels of the serine protease inhibitor alpha-1-antitrypsin, possibly affecting the anti-inflammatory action of HDL. They also showed increased levels of TTR, which might increase the risk of apoA-I truncation, leading to reduced cholesterol efflux, as well as causing apoA-I to become amyloidogenic [Liz et al. 2007]. The K131del mutation has previously been associated with apoA-I amyloid depositions [Amarzguioui et al. 1998]. Since amyloid depositions of apoA-I are 
present in atherosclerotic lesions and believed to contribute to CVD [Teoh et al. 2011], the increase of TTR may be detrimental.

In Paper II, a study of the effects of the P297S mutation in SR-B1 was initiated to elucidate whether reduced functionality of this receptor is associated with altered lipoprotein proteome and function. The heterozygote carriers of the mutation showed an apparent increase of HDL-C, accompanied by an increase of non-glycosylated and possibly fragmented apoL-1 in HDL. The increase of these apoL-1 isoforms may indicate modification of the protein due to prolonged time in the circulation as a direct consequence of dysfunctional SR-B1, but this needs to be further studied. The heterozygotes also showed increased levels of apoE in LDL as well as of free apoE. ApoE is an interesting protein with different functions depending on its localization; in LDL it facilitates the uptake of LDL particles by hepatic receptors, while free apoE may facilitate the cholesterol uptake of SR-B1 [Bultel-Brienne et al. 2002]. The increase of apoE in these fractions might contribute to a compensatory mechanism contributing to an increased cholesterol uptake when SR-B1 is less functional.

HDL apoA-I from SR-B1 P297S heterozygotes showed increased levels of methionine oxidations, although not associated with reduced cholesterol efflux or anti-oxidative capability, contrary to what other studies have found [Shao et al. 2014, Zerrad-Saadi et al. 2009]. It is possible that some of the proteomic changes observed, including increased apoL-1 in HDL or free apoE, may affect cholesterol efflux or anti-oxidative function. As such, apoL-1 is mainly expressed in the more anti-oxidative HDL3 fraction, and low levels of apoL-1 have recently been proposed as a predictor for future CVD [Cubedo et al. 2016]. However, the effect of apoL-1 and its glycosylation in anti-oxidative and cholesterol efflux mechanisms remains to be determined. Methionine oxidations have also been shown to induce full-length apoA-I to form amyloid fibrils [Wong et al. 2010, Chan et al. 2015], indicating a potential detrimental consequence in the heterozygotes.

Animal studies have provided, and continue to contribute, crucial information regarding the HDL system. However, differences between species can make the interpretation of findings in animal models towards human physiology difficult. An example is that mice lack CETP, and thus transport cholesterol in HDL rather than in LDL, as is the case in humans. In the light of this, studies of mutations in central HDL proteins in humans provide an interesting opportunity to gain insight into how alteration in the protein affects HDL structure, function and metabolism. A major drawback of studying rare mutations such as P297S is that the power of finding an association with functional effects is low. Therefore, it's interesting that a recently identified mutation in SR-B1 (P376L), causing increased HDL-C, was analyzed in 16 genetic sample sets (including approximately 130 000 individuals) revealing 86 carriers of the mutation, incurring an odds ratio of 1.76 for 
CVD as compared to non-carriers [Zanoni et al. 2016]. This increase in odds ratio provides further evidence that SR-B1 function is antiatherogenic in humans and enhancing SR-B1 function may be a novel target for therapy.

Papers I and II provide data on the proteomic changes in HDL particles due to mutations in apoA-I and its interacting receptor SR-B1. Where mutations in apoA-I lead to particles with reduced anti-inflammatory and cholesterol efflux functions, HDL from SR-B1 heterozygotes appears to have unaltered functions, although it appears to be more oxidized. These studies show how lipoproteomic analyses may be useful for investigating mutations in central actors of the HDL metabolism to enhance the understanding of how these proteins affect individuals. 


\section{Environmental pollutants and HDL (Papers III and IV)}

POPs are a heterogeneous collection of persistent chemicals, wherein an increasing amount of research has linked POPs to many diseases, including CVD, diabetes, and cancers. Relatively little is known about the relationship between POPs and lipoproteins. Early in vitro studies demonstrated lipoprotein's capacity to transport POPs [Maliwal and Guthrie 1982, Vomachka et al. 1983], and their levels in lipoprotein fractions [Norén et al. 1999]; however, the association between lipoprotein-associated POPs and CVD is not studied thus far. To investigate this, blood samples from a previously studied population, living in a historically contaminated community, were used.

In Paper III, HDL and LDL/VLDL were isolated by ultracentrifugation for subsequent analysis of POP levels from 28 non-smoking individuals with CVD or cancer, or without any known diseases, out of a population of 78 individuals. The method used for analyzing POPs was described in 2012 and allows the analysis of 20 different POPs in a small volume [Salihovic et al. 2012], making it well suited for ultracentrifuge-derived lipoprotein fractions. Older methodologies required much larger volumes of starting material [Norén et al. 1999], making analyses of clinical samples difficult. Our analysis of lipoproteinassociated POPs detected 18 different compounds, including 14 PCB congeners and four OCPs.

Individuals with CVD or cancer showed significantly increased levels of several individual POPs, in addition to the summary measurements of PCB congeners (sumPCB) and POPs (sumPOP) in HDL and LDL/VLDL compared to the healthy individuals. Since POPs can act in a pro-inflammatory manner through different mechanisms, we hypothesized that increased levels of POPs reduce HDL functionality. To test this hypothesis, PON1 arylesterase activity was investigated in the study population and analyzed against the sumPCB values in plasma. The analysis showed that higher levels of sumPCB were associated with reduced PON1 activity, indicating that levels of POPs are inversely associated with HDL anti-oxidative function.

Highly chlorinated PCB congeners are known to be more persistent than less chlorinated congeners, and have been shown to be related to CVD risk markers. We found that higher chlorinated congeners were preferentially located in HDL and LDL/VLDL as compared to plasma. This preferential distribution could possibly indicate that these persistent molecules interfere with lipoprotein function, therefore leading to an increased risk of CVD. Considering the finding of reduced PON1 activity with increasing levels of sumPCB, it seems possible that such HDL effect will represent a mechanism in the POP-associated increase of CVD risk. 
In Paper IV, we studied a subsample of seven healthy and ten CVD individuals from Paper III. The proteome of HDL, isolated by ultracentrifugation, was analyzed with nLCMS/MS, which led to the identification of 118 proteins. Of the identified proteins, ten were found to be associated with the levels of sumPOP, or with the sum of highly chlorinated PCB congeners (sumPCB-HC). The two lipid transfer proteins, CETP and PLTP, were positively associated with the sumPOP and/or sumPCB-HC. These two proteins have a rather unclear association with CVD, as conflicting studies have shown that they can be protective or detrimental [Albers et al. 2012, Hovingh et al. 2015].

Other significant proteins/functions found include SAA, which reduce the antiinflammatory effects of HDL, and PON1 activity, which acts anti-oxidative. The ratio of these two, SAA/PON1, has been proposed as a possible marker for dysfunctional HDL [Kotani et al. 2013]. Interestingly, sumPCB-HC, which was found preferentially located in HDL in Paper III, was found to be positively associated with detrimental SAA and SAA/PON1 and negatively associated with protective PON1 activity. Combined, these proteomic changes indicate that sumPCB-HC may contribute to, or be a marker for, the generation or presence of dysfunctional HDL.

The nLC-MS/MS methodology allows higher throughput compared to 2-DE and can detect lower quantities of proteins from less starting material. A drawback is that the method cannot differentiate between some types of isoforms, including truncations of proteins. It does, however, allow the identification and quantification of other PTMs, such as methionine oxidations. Since apoA-I methionine oxidations are known to affect the functional properties of HDL [Shao et al. 2008, Zerrad-Saadi et al. 2009], the spectra obtained from nLC-MS/MS were searched against apoA-I with methionine oxidation as a variable modification. There were associations approaching significance between sumPOP and oxidations of methionine at position $110(0.6 \pm 0.3$, standardized regression coefficient $\pm \mathrm{SD}, \mathrm{p}=0.09)$ and $172(0.5 \pm 0.3, \mathrm{p}=0.09)$. Although these results were not statistically significant, they indicate that POP exposure may be linked to an increasing degree of methionine oxidation in apoA-I. Given its potential clinical importance in CVD [Shao et al. 2014], this should be further investigated in a larger sample.

Papers III and IV describe a novel method for POP analysis in lipoproteins that allows quantification of POPs in clinical samples not possible previously. Combined, our analyses suggest a novel link between HDL, POPs and CVD. These findings provide insight into a possible mechanism of how POPs may increase the risk of CVD. However, delineating the possibility of casual mechanisms underlying these findings are necessary to confirm a direct relationship between POPs, their presence in lipoproteins and CVD risk. 


\section{Concluding remarks and future perspectives}

HDL represents a complex set of particles interacting with other lipoproteins as well as with many different cells and receptors. These particles have been extensively studied due to their protective effects against CVD and other inflammation-dependent diseases. Along with increasing data implying that HDL-C alone does not adequately explain the protective properties of HDL, there is an increasing need to find new measurements or functions that may better explain and/or predict the CVD risk. Lipoproteomics allows the identification and quantification of HDL protein content, including a wide variety of potentially important isoforms.

This thesis demonstrates proteomic alterations in HDL of heterozygotes with mutations causing changes in the levels of HDL-C. The different mutations cause various changes in the proteome that may alter the functionality of the particles, but also reveal interesting potential biomarkers for further studies in relation to CVD. Throughout the two studies, an extensive set of methods has been employed that could be used in further lipoproteomic studies aiming to better understand the HDL system. As such, the nLC-MS/MS methodology may be of particular interest since it allows high-throughput analysis of proteins and certain PTMs simultaneously. Future studies should focus on delineating the effect of the identified proteomic alterations on different aspects of HDL. In this respect, there are several important questions to be addressed. Are the proteomic changes causally responsible for the functional alterations or do they represent markers of the alterations? Can they represent a feedback mechanism to normalize the functions? How does HDL retention time relate to alterations in protein isoforms, and is this detrimental? A general focus for future studies should include the separate analysis of HDL2 and HDL3 to investigate how genetic mutations affect each of the different subclasses. Another important aspect is to study the lipidome of HDL and elucidate how this relates to the proteome and functions.

POPs are common in the environment and constitute a significant exposure risk for the general population. With increasing evidence pointing towards POPs being a risk factor for CVD, the HDL system constitutes a possible target and mediator. Indeed, the HDL system was found to transport POPs, and this was associated with changes in the proteome and HDL functions, providing a possible mechanistic link between POPs and CVD. Future studies of POPs and HDL should include an expansion of the analyses to a larger population in order to verify findings, and to provide increased statistical power in detection of other possibly affected proteins and functions. Studies should also focus on establishing a better concept of the functional consequences of POP loading in HDL. Are the POPs directly interfering with normal HDL function, or are inflammatory components in interacting cells and tissues altering the HDL particles? Do the POPs alter the HDL 
particles in other aspects such as the lipidome? Finally, the investigated POPs only contribute a small number of pollutants, and future research should also focus on whether other pollutants affect HDL composition/function and whether these "newly" identified pollutants act with POPs synergistically. Possible pollutants of interest include perfluorinated compounds such as perfluorooctanoic acid/perfluorooctanesulfonic acid (PFOA/PFOS), which have been found to influence levels of circulating lipids including HDL-C [Geiger et al. 2014, Wang et al. 2012].

To conclude, lipoproteomic analyses of HDL, as employed throughout this thesis, provide valuable data for understanding the HDL system in relation to factors such as genetic mutations or pollutants. With developments in instrumentation and analytical techniques, lipoproteomics has identified a wide array of proteins located in HDL. The next step involves adding the perspective of the importance of isoforms and subfractions of HDL, and how all of these factors together control the plethora of functions that HDL has been ascribed. Then, hopefully, we can answer the question of which aspects of HDL should be a target to enhance a protective population of particles capable of reducing the risk of CVD. 


\section{References}

Al-Salman F., Plant N. Non-coplanar polychlorinated biphenyls (PCBs) are direct agonists for the human pregnane-X receptor and constitutive androstane receptor, and activate target gene expression in a tissue-specific manner. Toxicol Appl Pharmacol. 2012;263:713.

Albers J.J., Cheung M.C. Emerging roles for phospholipid transfer protein in lipid and lipoprotein metabolism. Curr Opin Lipidol. 2004;15:255-260.

Albers J.J., Vuletic S., Cheung M.C. Role of plasma phospholipid transfer protein in lipid and lipoprotein metabolism. Biochim Biophys Acta. 2012;1821:345-357.

Alwaili K., Bailey D., Awan Z., Bailey S.D. et al. The HDL proteome in acute coronary syndromes shifts to an inflammatory profile. Biochim Biophys Acta. 2012;1821:405-415.

Amarzguioui M., Mucchiano G., Häggqvist B., Westermark P. et al. Extensive intimal apolipoprotein A1-derived amyloid deposits in a patient with an apolipoprotein A1 mutation. Biochem Biophys Res Commun. 1998;242:534-539.

Aminov Z., Haase R.F., Pavuk M., Carpenter D.O. et al. Analysis of the effects of exposure to polychlorinated biphenyls and chlorinated pesticides on serum lipid levels in residents of Anniston, Alabama. Environ Health. 2013;12:108.

Annema W., von Eckardstein A. High-density lipoproteins. Multifunctional but vulnerable protections from atherosclerosis. Circ J. 2013;77:2432-2348.

Argraves K.M., Gazzolo P.J., Groh E.M., Wilkerson B.A. et al. High density lipoproteinassociated sphingosine 1-phosphate promotes endothelial barrier function. J Biol Chem. 2008;283:25074-25081.

Bass D.A., Parce J.W., Dechatelet L.R., Szejda P. et al. Flow cytometric studies of oxidative product formation by neutrophils: a graded response to membrane stimulation. J Immunol. 1983;130:1910-1917.

Bergman A., Klasson-Wehler E., Kuroki H. Selective retention of hydroxylated PCB metabolites in blood. Environ Health Perspect. 1994;102:464-469.

Besler C., Heinrich K., Rohrer L., Doerries C. et al. Mechanisms underlying adverse effects of HDL on eNOS-activating pathways in patients with coronary artery disease. J Clin Invest. 2011;121:2693-2708. 
Brunham L., Tietjen I., Bochjem A., Singaraja R. et al. Novel mutations in scavenger receptor BI associated with high HDL cholesterol in humans. Clin Genet. 2011;79:575581.

Bultel-Brienne S., Lestavel S., Pilon A., Laffont I. et al. Lipid free apoE binds to the class B type I Scavenger Receptor 1 (SR-B1) and enhances cholesteryl ester uptake from lipoproteins. J Biol Chem. 2002;277:36092-36099.

Cárdenas-González M., Gaspar-Ramírez O., Pérez-Vázquez F.J., Alegría-Torres J.A. et al. p,p'-DDE, a DDT metabolite, induces proinflammatory molecules in human peripheral blood mononuclear cells "in vitro". Exp Toxicol Pathol. 2013;65:661-665.

Chadwick A., Sahoo D. Functional characterization of newly-discovered mutations in human SR-BI. PLoS ONE. 2012;7:e45660.

Chan G.K., Witkowski A., Gantz D.L., Zhang T.O. et al. Myeloperoxidase-mediated Methionine Oxidation Promotes an Amyloidogenic Outcome for Apolipoprotein A-I. J Biol Chem. 2015;290:10958-10971.

Checa A., Bedia C., Jaumot J. Lipidomic data analysis: tutorial, practical guidelines and applications. Anal Chim Acta. 2015;885:1-16.

Cholesterol Treatment Trialists' (CTT) Collaboration. Efficacy and safety of LDL-lowering therapy among men and women: meta-analysis of individual data from 174,000 participants in 27 randomised trials. Lancet. 2015;385:1397-1405.

Christoffersen C., Nielsen L.B., Axler O., Andersson A. et al. Isolation and characterization of human apolipoprotein M-containing lipoproteins. J Lipid Res. 2006;47:1833-1843.

Christoffersen C., Ahnström J., Axler O., Christensen E.I. et al. The signal peptide anchors apolipoprotein $\mathrm{M}$ in plasma lipoproteins and prevents rapid clearance of apolipoprotein $\mathrm{M}$ from plasma. J Biol Chem. 2008;283:18765-18772.

Christoffersen C., Obinata H., Kumaraswamy S.B., Galvani S. et al. Endotheliumprotective sphingosine-1-phosphate provided by HDL-associated apolipoprotein M. Proc Natl Acad Sci U S A. 2011;108:9613-9618.

Contiero E., Ferrari R., Vaselli G.M., Folin M. Apolipoprotein AI isoforms in serum determined by isoelectric focusing and immunoblotting. Electrophoresis. 1997;18:122-126.

Cox J., Mann M. MaxQuant enables high peptide identification rates, individualized p.p.b.range mass accuracies and proteome-wide protein quantification. Nat Biotechnol. 2008;26:1367-1372. 
Cox J., Michalski A., Mann M. Software lock mass by two-dimensional minimization of peptide mass errors. J Am Soc Mass Spectrom. 2011;22:1373-1380.

Cox J., Hein M.Y., Luber C.A., Paron I. et al. Accurate proteome-wide label-free quantification by delayed normalization and maximal peptide ratio extraction, termed MaxLFQ. Mol Cell Proteomics. 2014;13:2513-2526.

Crofton K.M., Craft E.S., Hedge J.M., Gennings C. et al. Thyroid-hormone-disrupting chemicals: evidence for dose-dependent additivity or synergism. Environ Health Perspect. 2005;113:1549-1554.

Cubedo J., Padró T., Alonso R., Mata P. et al. ApoL1 levels in high density lipoprotein and cardiovascular event presentation in patients with familial hypercholesterolemia. J Lipid Res. 2016;57:1059-1073.

Cuchel M., Lund-Katz S., de la Llera-Moya M., Millar J.S. et al. Pathways by which reconstituted high-density lipoprotein mobilizes free cholesterol from whole body and from macrophages. Arterioscler Thromb Vasc Biol. 2010;30:526-532.

Daniil G., Phedonos A.A., Holleboom A.G., Motazacker M.M. et al. Characterization of antioxidant/anti-inflammatory properties and apoA-I-containing subpopulations of HDL from family subjects with monogenic low HDL disorders. Clin Chim Acta. 2011;412:12131220.

Danilo C., Gutierrez-Pajares J., Mainieri M., Mercier I. et al. Scavenger receptor class B type I regulates cellular cholesterol metabolism and cell signaling associated with breast cancer development. Breast Cancer Res. 2013;15:R87.

Davidson M., Toth P. High-density lipoprotein metabolism: potential therapeutic targets. Am J Cardiol. 2007;100:32N-40N.

Davidson W.S., Silva R.A., Chantepie S., Lagor W.R. et al. Proteomic analysis of defined HDL subpopulations reveals particle-specific protein clusters: relevance to antioxidative function. Arterioscler Thromb Vasc Biol. 2009;29:870-876.

de Graaf J., Hendriks J.C., Demacker P.N., Stalenhoef A.F. Identification of multiple dense LDL subfractions with enhanced susceptibility to in vitro oxidation among hypertriglyceridemic subjects. Normalization after clofibrate treatment. Arterioscler Thromb Vasc Biol. 1993;13:712-719. 
de Souza J.A., Vindis C., Nègre-Salvayre A., Rye K.A. et al. Small, dense HDL 3 particles attenuate apoptosis in endothelial cells: pivotal role of apolipoprotein A-I. J Cell Mol Med. 2010;14:608-620.

de Haan W., de Vries-van der Weij J., Mol I.M., Hoekstra M. et al. PXR agonism decreases plasma HDL levels in ApoE3-Leiden.CETP mice. Biochim Biophys Acta. 2009;1791:191197.

Dopico M., Gómez A. Review of the current state and main sources of dioxins around the world. J Air Waste Manag Assoc. 2015:9;1033-1049.

Ehlers M.R. Immune-modulating effects of alpha-1 antitrypsin. Biol Chem. 2014;395:11871193.

Elsøe S., Ahnström J., Christoffersen C., Hoofnagle A.N. et al. Apolipoprotein M binds oxidized phospholipids and increases the antioxidant effect of HDL. Atherosclerosis. 2012;221:91-97.

Fängström B., Athanasiadou M., Grandjean P., Weihe P. et al. Hydroxylated PCB metabolites and PCBs in serum from pregnant Faroese women. Environ Health Perspect. 2002;110:895-899.

Felty Q., Yoo C., Kennedy A. Gene expression profile of endothelial cells exposed to estrogenic environmental compounds: implications to pulmonary vascular lesions. Life Sci. 2010;86:919-927.

Filou S., Lhomme M., Karavia E.A., Kalogeropoulou C. et al. Distinct Roles of Apolipoproteins A1 and E in the Modulation of High-Density Lipoprotein Composition and Function. Biochemistry. 2016;55:3752-3762.

Furlong C.E., Marsillach J., Jarvik G.P., Costa L.G. Paraoxonases-1, -2 and -3: What are their functions? Chem Biol Interact. 2016. [Epub ahead of print]

Galvani S., Sanson M., Blaho V.A., Swendeman S.L. et al. HDL-bound sphingosine 1phosphate acts as a biased agonist for the endothelial cell receptor S1P1 to limit vascular inflammation. Sci Signal. 2015;8:ra79.

Geiger S.D., Xiao J., Ducatman A., Frisbee S. et al. The association between PFOA, PFOS and serum lipid levels in adolescents. Chemosphere. 2014;98:78-83.

Ghafouri B., Karlsson H., Mörtstedt H., Lewander A. et al. 2,5-Dihydroxybenzoic acid instead of alpha-cyano-4-hydroxycinnamic acid as matrix in matrix-assisted laser 
desorption/ionization time-of-flight mass spectrometry for analyses of in-gel digests of silver-stained proteins. Anal Biochem. 2007;371:121-123.

Ghiselli G., Rohde M.F., Tanenbaum S., Krishnan S. et al. Origin of apolipoprotein A-I polymorphism in plasma. J Biol Chem. 1985;260:15662-15668.

Gordts P.L., Nock R., Son N.H., Ramms B. et al. ApoC-III inhibits clearance of triglyceride-rich lipoproteins through LDL family receptors. J Clin Invest. 2016;126:28552866.

Görg A., Drews O., Lück C., Weiland F. et al. 2-DE with IPGs. Electrophoresis. 2009;30 Suppl 1:S122-S132.

Grimm F.A., Hu D., Kania-Korwel I., Lehmler H.J. et al. Metabolism and metabolites of polychlorinated biphenyls. Crit Rev Toxicol. 2015;45:245-272.

Ha M.H., Lee D.H., Jacobs D.R. Association between serum concentrations of persistent organic pollutants and self-reported cardiovascular disease prevalence: results from the National Health and Nutrition Examination Survey, 1999-2002. Environ Health Perspect. 2007;115:1204-1209.

Hafiane A., Genest J. High density lipoproteins: Measurement techniques and potential biomarkers of cardiovascular risk. BBA Clin. 2015;3:175-88.

Hamers T., Kamstra J.H., Cenijn P.H., Pencikova K. et al. In vitro toxicity profiling of ultrapure non-dioxin-like polychlorinated biphenyl congeners and their relative toxic contribution to PCB mixtures in humans. Toxicol Sci. 2011;121:88-100.

Han C.Y., Tang C., Guevara M.E., Wei H. et al. Serum amyloid A impairs the antiinflammatory properties of HDL. J Clin Invest. 2016;126:266-281.

Havel R., Eder H., Bragdon J. The distribution and chemical composition of ultracentrifugally separated lipoproteins in human serum. J Clin Invest. 1955;34:1345-1353.

Helkin A., Stein J.J., Lin S., Siddiqui S. et al. Dyslipidemia Part 1--Review of Lipid Metabolism and Vascular Cell Physiology. Vasc Endovascular Surg. 2016;50:107-118.

Helmfrid I., Berglund M., Lofman O., Wingren G. Health effects and exposure to polychlorinated biphenyls (PCBs) and metals in a contaminated community. Environ Int. 2012;44:53-58.

Ho C.S., Lam C.W., Chan M.H., Cheung R.C. et al. Electrospray ionisation mass spectrometry: principles and clinical applications. Clin Biochem Rev. 2003;24:3-12. 
Holleboom A.G., Karlsson H., Lin R.S., Beres T.M. et al. Heterozygosity for a loss-offunction mutation in GALNT2 improves plasma triglyceride clearance in man. Cell Metab. 2011;14:811-818.

Holleboom A., Jakulj L., Franssen R., Decaris J. et al. In vivo cholesterol efflux is reduced in carriers of a mutation in APOA1. J Lipid Res. 2013;54:1964-1971.

Hovingh G., Brownlie A., Bisoendial R., Dube, M. et al. A novel ApoA-I mutation (L178P) leads to endothelial dysfunction, increased arterial wall thickness, and premature coronary artery disease. J Am Coll Cardiol. 2004;44:1429-1435.

Hortin G.L. The MALDI-TOF mass spectrometric view of the plasma proteome and peptidome. Clin Chem. 2006;52:1223-1237.

Hovingh G.K., Ray K.K., Boekholdt S.M. Is Cholesteryl Ester Transfer Protein Inhibition an Effective Strategy to Reduce Cardiovascular Risk? CETP as a Target to Lower CVD Risk: Suspension of Disbelief? Circulation. 2015;132:433-440.

Huang R., Silva R.A., Jerome W.G., Kontush A. et al. Apolipoprotein A-I structural organization in high-density lipoproteins isolated from human plasma. Nat Struct Mol Biol. 2011;18:416-422.

Huang Y., Wu Z., Riwanto M., Gao S. et al. Myeloperoxidase, paraoxonase-1, and HDL form a functional ternary complex. J Clin Invest. 2013;123:3815-3528.

Ito K., Bick A., Flannick J., Friedman D. et al. Increased burden of cardiovascular disease in carriers of APOL1 genetic variants. Circ Res. 2014;114:845-850.

a Karlsson H., Leandersson P., Tagesson C., Lindahl M. Lipoproteomics I: Mapping of proteins in low-density lipoprotein using two-dimensional gel electrophoresis and mass spectrometry. Proteomics. 2005;5:551-565.

b Karlsson H., Leandersson P., Tagesson C., Lindahl M., Lipoproteomics II: Mapping of proteins in high-density lipoprotein using two-dimensional gel electrophoresis and mass spectrometry. Proteomics. 2005;5:1431-1445.

Karlsson H., Lindqvist H., Tagesson C., Lindahl M. Characterization of apolipoprotein M isoforms in low-density lipoprotein. J Proteome Res. 2006;5:2685-2690.

Kato N., Momota Y., Kusuhara T. Changes in distribution of alpha-tocopherol and cholesterol in serum lipoproteins and tissues of rats by dietary PCB and dietary level of protein. J Nutr Sci Vitaminol (Tokyo). 1989;35:655-660. 
Khera A., Cuchel M., de la Llera-Moya M., Rodrigues A. et al. Cholesterol efflux capacity, high-density lipoprotein function, and atherosclerosis. N Engl J Med. 2011;364:127-135.

Khersonsky O., Tawfik D.S. Structure-reactivity studies of serum paraoxonase PON1 suggest that its native activity is lactonase. Biochemistry. 2005;44:6371-6382.

Khetarpal S.A., Schjoldager K.T., Christoffersen C., Raghavan A. et al. Loss of Function of GALNT2 Lowers High-Density Lipoproteins in Humans, Nonhuman Primates, and Rodents. Cell Metab. 2016;24:234-245.

Kim M.J., Pelloux V., Guyot E., Tordjman J. et al. Inflammatory pathway genes belong to major targets of persistent organic pollutants in adipose cells. Environ Health Perspect. 2012;120:508-514.

Kim S.A., Kim K.S., Lee Y.M., Jacobs D.R. et al. Associations of organochlorine pesticides and polychlorinated biphenyls with total, cardiovascular, and cancer mortality in elders with differing fat mass. Environ Res. 2015;138:1-7.

Kimura T., Tomura H., Sato K., Ito M. et al. Mechanism and role of high density lipoprotein-induced activation of AMP-activated protein kinase in endothelial cells. J Biol Chem. 2010;285:4387-4397.

Kingwell B.A., Chapman M.J., Kontush A., Miller N.E. HDL-targeted therapies: progress, failures and future. Nat Rev Drug Discov. 2014;13:445-464.

Kontush A., Chantepie S., Chapman M.J. Small, dense HDL particles exert potent protection of atherogenic LDL against oxidative stress. Arterioscler Thromb Vasc Biol. 2003;23:1881-1888.

Kontush A. HDL-mediated mechanisms of protection in cardiovascular disease. Cardiovasc Res. 2014;103:341-349.

Kontush A., Lindahl M., Lhomme M., Calabresi L. et al. Structure of HDL: particle subclasses and molecular components. Handb Exp Pharmacol. 2015;224:3-51.

Kotani K., Yamada T., Gugliucci A. Paired Measurements of Paraoxonase 1 and Serum Amyloid A as Useful Disease Markers. Biomed Res Int. 2013;2013:481437.

Kumar J., Monica Lind P., Salihovic S., van Bavel B. et al. Influence of persistent organic pollutants on oxidative stress in population-based samples. Chemosphere. 2014;114:303309. 
Lans M.C., Klasson-Wehler E., Willemsen M., Meussen E. et al. Structure-dependent, competitive interaction of hydroxy-polychlorobiphenyls, -dibenzo-p-dioxins and dibenzofurans with human transthyretin. Chem Biol Interact. 1993;88:7-21.

Lee-Rueckert M., Escola-Gil J.C., Kovanen P.T. HDL functionality in reverse cholesterol transport - Challenges in translating data emerging from mouse models to human disease. Biochim Biophys Acta. 2016;1861:566-583.

Levels J.H., Geurts P., Karlsson H., Marée R. et al. High-density lipoprotein proteome dynamics in human endotoxemia. Proteome Sci. 2011;9:34.

Li X.M., Tang W.H., Mosior M.K., Huang Y. et al. Paradoxical association of enhanced cholesterol efflux with increased incident cardiovascular risks. Arterioscler Thromb Vasc Biol. 2013;33:1696-1705.

Lind P.M., van Bavel B., Salihovic S., Lind L. Circulating levels of persistent organic pollutants (POPs) and carotid atherosclerosis in the elderly. Environ Health Perspect. 2012;120:38-43.

Lind L., Lind P.M. Can persistent organic pollutants and plastic-associated chemicals cause cardiovascular disease? J Intern Med. 2012;271:537-553.

Liz M.A., Gomes C.M., Saraiva M.J., Sousa M.M. ApoA-I cleaved by transthyretin has reduced ability to promote cholesterol efflux and increased amyloidogenicity. J Lipid Res. 2007;48:2385-2395.

Lopez M.F., Berggren K., Chernokalskaya E., Lazarev A. et al. A comparison of silver stain and SYPRO Ruby Protein Gel Stain with respect to protein detection in two-dimensional gels and identification by peptide mass profiling. Electrophoresis. 2000;21:3673-3683.

Mackey R.H., Greenland P., Goff D.C. Jr., Lloyd-Jones D. et al. High-density lipoprotein cholesterol and particle concentrations, carotid atherosclerosis, and coronary events: MESA (multi-ethnic study of atherosclerosis). J Am Coll Cardiol. 2012;60:508-516.

Mackness M., Mackness B. Human paraoxonase-1 (PON1): Gene structure and expression, promiscuous activities and multiple physiological roles. Gene. 2015;567:12-21.

Maliwal B.P., Guthrie F.E. In vitro uptake and transfer of chlorinated hydrocarbons among human lipoproteins. J Lipid Res. 1982;23:474-479.

Mangum L.C., Borazjani A., Stokes J.V., Matthews A.T. et al. Organochlorine insecticides induce NADPH oxidase-dependent reactive oxygen species in human monocytic cells via phospholipase A2/arachidonic acid. Chem Res Toxicol. 2015;28:570-584. 
Marengo E., Robotti E. Biomarkers for pancreatic cancer: recent achievements in proteomics and genomics through classical and multivariate statistical methods. World J Gastroenterol. 2014;20:13325-13342.

Matsuura F., Wang N., Chen W., Jiang X.C. et al. HDL from CETP-deficient subjects shows enhanced ability to promote cholesterol efflux from macrophages in an apoE- and ABCG1-dependent pathway. J Clin Invest. 2006;116:1435-1442.

McGarrah R.W., Craig D.M., Haynes C., Dowdy Z.E. et al. High-density lipoprotein subclass measurements improve mortality risk prediction, discrimination and reclassification in a cardiac catheterization cohort. Atherosclerosis. 2016;246:229-235.

Meerts I.A., van Zanden J.J., Luijks E.A., van Leeuwen-Bol I. et al. Potent competitive interactions of some brominated flame retardants and related compounds with human transthyretin in vitro. Toxicol Sci. 2000;56:95-104.

Megger D.A., Bracht T., Meyer H.E., Sitek B. Label-free quantification in clinical proteomics. Biochim Biophys Acta. 2013;1834:1581-1590.

Nakajima K., Nakano T., Tokita Y., Nagamine T. et al. Postprandial lipoprotein metabolism: VLDL vs chylomicrons. Clin Chim Acta. 2011;412:1306-1318.

Navab M., Hama S.Y., Hough G.P., Subbanagounder G. et al. A cell-free assay for detecting HDL that is dysfunctional in preventing the formation of or inactivating oxidized phospholipids. J Lipid Res. 2001;42:1308-1317.

Nicolardi S., van der Burgt Y.E., Dragan I., Hensbergen P.J. et al. Identification of new apolipoprotein-CIII glycoforms with ultrahigh resolution MALDI-FTICR mass spectrometry of human sera. J Proteome Res. 2013;12:2260-2268.

Nofer J.R., van der Giet M., Tölle M., Wolinska I. et al. HDL induces NO-dependent vasorelaxation via the lysophospholipid receptor S1P3. J Clin Invest. 2004;113:569-581.

Norén K, Weistrand C, Karpe F. Distribution of PCB congeners, DDE, hexachlorobenzene, and methylsulfonyl metabolites of PCB and DDE among various fractions of human blood plasma. Arch Environ Contam Toxicol. 1999;37:408-414 .

Oda H., Yoshida A. Effect of Feeding Xenobiotics on Serum High Density Lipoprotein and Apolipoprotein A-I in Rats, Biosci Biotechnol Biochem. 1994;9:1646-1651.

Ono K., Horie T., Nishino T., Baba O. et al. MicroRNAs and High-Density Lipoprotein Cholesterol Metabolism. Int Heart J. 2015;56:365-371. 
Paramel Varghese G., Folkersen L., Strawbridge R.J., Halvorsen B. et al. NLRP3 Inflammasome Expression and Activation in Human Atherosclerosis. J Am Heart Assoc. 2016;5:e003031.

Patel P.J., Khera A.V., Jafri K., Wilensky R.L. et al. The anti-oxidative capacity of highdensity lipoprotein is reduced in acute coronary syndrome but not in stable coronary artery disease. J Am Coll Cardiol. 2011;58:2068-2075.

Penell J., Lind L., Salihovic S., van Bavel B. et al. Persistent organic pollutants are related to the change in circulating lipid levels during a 5 year follow-up. Environ Res. 2014;134:190-197.

Perkins J.T., Petriello M.C., Newsome B.J., Hennig B. Polychlorinated biphenyls and links to cardiovascular disease. Environ Sci Pollut Res Int. 2016;23:2160-2172.

Pownall H.J., Gotto A.M. Jr. 1999, Lipoproteins in Health and Disease, Arnold Publishers, 3-15

Pownall H.J., Gotto A.M. Jr. New Insights into the High-Density Lipoprotein Dilemma. Trends Endocrinol Metab. 2016;27:44-53.

Pu L.J., Lu L., Zhang R.Y., Du R. et al. Glycation of apoprotein A-I is associated with coronary artery plaque progression in type 2 diabetic patients. Diabetes Care. 2013;36:13121320 .

Quintana F.J. The aryl hydrocarbon receptor: a molecular pathway for the environmental control of the immune response. Immunology. 2013;138:183-189.

Ramasamy I. Recent advances in physiological lipoprotein metabolism. Clin Chem Lab Med. 2014;52:1695-1727.

Richter R., Jarvik G., Furlong C. Determination of Paraoxonase 1 Status Without the Use of Toxic Organophosphate Substrates. Circ Cardiovasc Genet. 2008;1:147-152.

Rasmiena A.A., Barlow C.K., Ng T.W., Tull D. et al. High density lipoprotein efficiently accepts surface but not internal oxidised lipids from oxidised low density lipoprotein. Biochim Biophys Acta. 2016;1861:69-77.

Rohatgi A., Khera A., Berry J.D., Givens E.G. et al. HDL cholesterol efflux capacity and incident cardiovascular events. N Engl J Med. 2014;371:2383-2393.

Rosenson R.S., Brewer H.B. Jr., Ansell B.J., Barter P. et al. Dysfunctional HDL and atherosclerotic cardiovascular disease. Nat Rev Cardiol. 2016;13:48-60. 
Röhrl C., Stangl H. HDL endocytosis and resecretion. Biochim Biophys Acta. 2013;1831:1626-1633.

Saleheen D., Scott R., Javad S., Zhao W. et al. Association of HDL cholesterol efflux capacity with incident coronary heart disease events: a prospective case-control study. Lancet Diabetes Endocrinol. 2015;3:507-513.

Salihovic S., Mattioli L., Lindström G., Lind L. et al. A rapid method for screening of the Stockholm Convention POPs in small amounts of human plasma using SPE and HRGC/HRMS. Chemosphere. 2012;86:747-753.

Schmidt C., Bergström G. Apolipoprotein B/apolipoprotein A-I ratio and apolipoprotein $\mathrm{B}$ : long-term predictors of myocardial infarction in initially healthy middle-aged men--a 13year follow-up. Angiology. 2014;65:901-905.

Schrutka L., Goliasch G., Meyer B., Wurm R. et al. Impaired High-Density Lipoprotein Anti-Oxidant Function Predicts Poor Outcome in Critically Ill Patients. PLoS One. 2016;11:e0151706.

Sergeev A.V., Carpenter D.O. Exposure to persistent organic pollutants increases hospitalization rates for myocardial infarctionwith comorbid hypertension. Prim Prev Insights. 2010;2:1-9.

Settasatian N., Duong M., Curtiss L.K., Ehnholm C. et al. The mechanism of the remodeling of high density lipoproteins by phospholipid transfer protein. J Biol Chem. 2001;276:26898-26905.

Shao B., Cavigiolio G., Brot N., Oda M. et al. Methionine oxidation impairs reverse cholesterol transport by apolipoprotein A-I. Proc Natl Acad Sci U S A. 2008;105:1222412229.

Shao B., Tang C., Sinha A., Mayer P. et al. Humans With Atherosclerosis Have Impaired ABCA1 Cholesterol Efflux and Enhanced High-Density Lipoprotein Oxidation by Myeloperoxidase. Circ Res. 2014;114:1733-1742.

Shan Q., Wang J., Huang F., Lv X. et al. Augmented atherogenesis in ApoE-null mice coexposed to polychlorinated biphenyls and 2,3,7,8-tetrachlorodibenzo-p-dioxin. Toxicol Appl Pharmacol. 2014;276:136-146.

Shevchenko A., Wilm M., Vorm O., Mann M. Mass spectrometric sequencing of proteins silver-stained polyacrylamide gels. Anal Chem. 1996;68:850-858. 
Sorci-Thomas M., Thomas M. The effects of altered apolipoprotein A-I structure on plasma HDL concentration. Trends Cardiovasc Med. 2002;12:121-128.

Sporstøl M., Tapia G., Malerød L., Mousavi S.A. et al. Pregnane X receptor-agonists downregulate hepatic ATP-binding cassette transporter A1 and scavenger receptor class B type I. Biochem Biophys Res Commun. 2005;331:1533-1541.

Stockholm Convention Home Page, United Nations Environment Programme (UNEP). [2016-09-18].

Tabb M.M., Kholodovych V., Grün F., Zhou C. et al. Highly chlorinated PCBs inhibit the human xenobiotic response mediated by the steroid and xenobiotic receptor (SXR). Environ Health Perspect. 2004;112:163-169.

Tabet F., Vickers K.C., Cuesta Torres L.F., Wiese C.B. et al. HDL-transferred microRNA223 regulates ICAM-1 expression in endothelial cells. Nat Commun. 2014;5:3292.

Tall A.R., Yvan-Charvet L., Terasaka N., Pagler T. et al. HDL, ABC transporters, and cholesterol efflux: implications for the treatment of atherosclerosis. Cell Metab. 2008;7:365-375.

Tang W.H., Hartiala J., Fan Y., Wu Y. et al. Clinical and genetic association of serum paraoxonase and arylesterase activities with cardiovascular risk. Arterioscler Thromb Vasc Biol. 2012;32:2803-2812.

Tariq S.M., Sidhu M.S., Toth P.P., Boden W.E. HDL hypothesis: where do we stand now? Curr Atheroscler Rep. 2014;16:398.

Teoh C.L., Griffin M.D., Howlett G.J. Apolipoproteins and amyloid fibril formation in atherosclerosis. Protein Cell. 2011;2:116-127.

Terasaka N., Wang N., Yvan-Charvet L., Tall A.R. High-density lipoprotein protects macrophages from oxidized low-density lipoprotein-induced apoptosis by promoting efflux of 7-ketocholesterol via ABCG1. Proc Natl Acad Sci U S A. 2007;104:15093-15098.

Thacker S.G., Zarzour A., Chen Y., Alcicek M.S. et al. High Density Lipoprotein reduces inflammation from cholesterol crystals by inhibiting inflammasome activation. Immunology. 2016. [Epub ahead of print].

Thompson A., Danesh J. Associations between apolipoprotein B, apolipoprotein AI, the apolipoprotein B/AI ratio and coronary heart disease: a literature-based meta-analysis of prospective studies. J Intern Med. 2006;259:481-492. 
Tilly-Kiesi M., Qiuping Z., Ehnholm S., Kahri J. et al. ApoAIHelsinki (Lys107 $\rightarrow 0$ ) associated with reduced HDL cholesterol and LpA-I:A-II deficiency. Arterioscler Thromb Vasc Biol. 1995;15:1294-1306.

Troughton J.A., Woodside J.V., Yarnell J.W., Arveiler D. et al. Paraoxonase activity and coronary heart disease risk in healthy middle-aged males: the PRIME study. Atherosclerosis. 2008;197:556-563.

Uittenbogaard A., Shaul P.W., Yuhanna I.S., Blair A. et al. High density lipoprotein prevents oxidized low density lipoprotein-induced inhibition of endothelial nitric-oxide synthase localization and activation in caveolae. J Biol Chem. 2000;275:11278-11283.

Vaisar T., Pennathur S., Green P.S., Gharib S.A. et al. Shotgun proteomics implicates protease inhibition and complement activation in the antiinflammatory properties of HDL. J Clin Invest. 2007;117:746-756.

Vaisar T., Tang C., Babenko I., Hutchins P. et al. Inflammatory remodeling of the HDL proteome impairs cholesterol efflux capacity. J Lipid Res. 2015;56:1519-1530.

Vanhamme L., Paturiaux-Hanocq F., Poelvoorde P., Nolan D.P. et al. Apolipoprotein L-I is the trypanosome lytic factor of human serum. Nature. 2003;422:83-87.

Vanhollebeke B., Pays E. The function of apolipoproteins L. Cell Mol Life Sci. 2006;63:1937-1944.

Vergeer M., Korporaal S., Franssen R., Meurs I. et al. Genetic variant of the scavenger receptor B1 in humans. N Engl J Med. 2011;364:136-145.

Vickers K.C., Palmisano B.T., Shoucri B.M., Shamburek R.D. et al. MicroRNAs are transported in plasma and delivered to recipient cells by high-density lipoproteins. Nat Cell Biol. 2011;13:423-433.

Vomachka M.S., Vodicnik M.J., Lech J.J. Characteristics of 2,4,5,2',4',5'hexachlorobiphenyl distribution among lipoproteins in vitro. Toxicol Appl Pharmacol. 1983;70:350.

Vuilleumier N., Dayer J.M., von Eckardstein A., Roux-Lombard P. Pro- or antiinflammatory role of apolipoprotein A-1 in high-density lipoproteins? Swiss Med Wkly. 2013;143:w13781.

Wagner J., Riwanto M., Besler C., Knau A. et al. Characterization of levels and cellular transfer of circulating lipoprotein-bound microRNAs. Arterioscler Thromb Vasc Biol. 2013;33:1392-1400. 
Wahlang B., Petriello M.C., Perkins J.T., Shen S. et al. Polychlorinated biphenyl exposure alters the expression profile of microRNAs associated with vascular diseases. Toxicol In Vitro. 2016;35:180-187.

Wan G., Zhaorigetu S., Liu Z., Kaini R. et al. Apolipoprotein L1, a novel Bcl-2 homology domain 3-only lipid-binding protein, induces autophagic cell death. J Biol Chem. 2008;283:21540-21549.

Wang J., Zhang Y., Zhang W., Jin Y. et al. Association of perfluorooctanoic acid with HDL cholesterol and circulating miR-26b and miR-199-3p in workers of a fluorochemical plant and nearby residents. Environ Sci Technol. 2012;46:9274-9281.

Wang X., Collins H.L., Ranalletta M., Fuki I.V. et al. Macrophage ABCA1 and ABCG1, but not SR-BI, promote macrophage reverse cholesterol transport in vivo. J Clin Invest. 2007;117:2216-2224.

Wheeler J.G., Keavney B.D., Watkins H., Collins R. et al. Four paraoxonase gene polymorphisms in 11212 cases of coronary heart disease and 12786 controls: meta-analysis of 43 studies. Lancet. 2004;363:689-695.

Wheelock Å.M., Wheelock C.E. Trials and tribulations of 'omics data analysis: assessing quality of SIMCA-based multivariate models using examples from pulmonary medicine. Mol Biosyst. 2013;9:2589-2596.

Wohlin M., Sundstrom J., Andren B., Larsson A. et al. An echolucent carotid artery intima media complex is a new and independent predictor of mortality in an elderly male cohort. Atherosclerosis 2009;205:486-491.

Wold S., Sjöström M., Eriksson L. PLS-regression: a basic tool of chemometrics. Chemometr Intell Lab Syst. 2001;58:109-130.

Wong Y.Q., Binger K.J., Howlett G.J., Griffin M.D. Methionine oxidation induces amyloid fibril formation by full-length apolipoprotein A-I. Proc Natl Acad Sci U S A. 2010;107:1977-1982.

Yan L.R., Wang D.X., Liu H., Zhang X.X. et al. A pro-atherogenic HDL profile in coronary heart disease patients: an iTRAQ labelling-based proteomic approach. PLoS One. 2014;9:e98368.

Zanoni P., Khetarpal S.A., Larach D.B., Hancock-Cerutti W.F. et al, Rare variant in scavenger receptor BI raises HDL cholesterol and increases risk of coronary heart disease. Science. 2016;351:1166-1171. 
Zerrad-Saadi A., Therond P., Chantepie S., Couturier M. et al. HDL3-mediated inactivation of LDL-associated phospholipid hydroperoxides is determined by the redox status of apolipoprotein A-I and HDL particle surface lipid rigidity: relevance to inflammation and atherogenesis. Arterioscler Thromb Vasc Biol. 2009;29:2169-2175.

Zhang J., Xu J., Wang J., Wu C. et al. Prognostic Usefulness of Serum Cholesterol Efflux Capacity in Patients With Coronary Artery Disease. Am J Cardiol. 2016;117:508-514.

Zhou C., Tabb M.M., Nelson E.L., Grün F. et al. Mutual repression between steroid and xenobiotic receptor and NF-kappaB signaling pathways links xenobiotic metabolism and inflammation. J Clin Invest. 2006;116:2280-2289. 


\section{Acknowledgements}

There are many people who I would like to express my sincere gratitude towards for their contribution in different ways to this thesis and my time as a $\mathrm{PhD}$ student.

Mats Lindahl, my main supervisor, for taking me in and allowing me to develop as a researcher. It has been fun and stimulating years and I appreciate that you always take your time with all my questions. Thanks for keeping up with all the side projects and my commitments in DOMFIL.

Gun Wingren, my co-supervisor, for helping me take a step back and look at the bigger picture in scientific matters and helping me grow as a researcher. Thanks for trying to help me limit my commitments in different boards, even if I failed to listen most of the times.

Helen Karlsson, my co-supervisor, for being an amazing friend and supervisor. Thanks for all the energy you spread and for showing that with a positive attitude, anything is possible. I greatly appreciate all the laughs and that you showed that organization comes in different forms.

Jan Albert Kuivenhoven, mijn co-begeleider, voor het tonen dat kritisch denken, zelfs met de meest voor de hand liggende "feiten", soms nodig is. Ik waardeer de rondleiding door Groningen enorm, zittend achterop je fiets. Ik ben je nog een paar biertjes verschuldigd voor al het papierwerk dat ik jouw kant op stuurde.

Co-authors including Ingela Helmfrid for introducing me to the field of environmental medicine and being an excellent co-worker. Thanks for making sure I never run out of work. Maria Turkina for all help with the mass spectrometers, interesting discussions and laughs. Sofie Sundberg for being a good friend and being instrumental in me ending up at the Occupational and Environmental Medicine.

Thanks to all "off-site" co-authors in the articles including the people in the Netherlands: Johannes Levels, Andrea Bochem, Kees Hovingh, Adriaan Holleboom, Menno Vergeer, Jeroen Sierts, John Kastelein, in Greece: Letta Argyri, Christina Gkolfinopoulou, Angeliki Chroni, in Örebro: Samira Salihovic, Bert van Bavel, and last but not least Ulf Norinder and Mats Fredriksson.

Louise Fornander for teaching me some of the methods I used over the years and the value of keeping the lab in order. Thanks for being a good friend and the shared office. Liam Ward for being an excellent friend, co-worker and for all the fun times. Thanks for introducing me to Britizh/Irizh culture. Bijar Ghafouri for always having time for scientific questions/ponderings. Thanks for being a great friend and for all the pranks. Whenever your coffee-cup needs a cleaning, it's just to say the word. Patrik Olausson for 
being a great fellow $\mathrm{PhD}$ student, friend and for all the hockey-talk. I still don't want your upside-down eggshell. Karin Wåhlen for being a great friend and co-worker over the years. Thanks for always being there and the fun times (never forget Glenn). Anders "X:et" Carlsson for being a great friend and for all laughs, including the bad attempts at dialects. Niclas Stensson for being a great co-worker, friend and always keeping the lab in good mood. Johanna Lönn for the fun times around the lab.

Inger Nordén Larsson for all help, keeping me in check at the lab and always caring. Reza Nosratabi, Jan Andersson and Per Leandersson for great times around the fikatable and around the lab. Fredrik Nyqvist for being an excellent co-worker and the road trips around Sweden. Louise Eskilsson for all the help and always draining me of blood if needed. Anders Ljungman for all the hockey talk. Say, how many golds does LHC have? Bengt Ståhlbom for introducing me to occupational hygiene and allowing me time to finish this thesis.

Thanks to all other co-workers at Occupational and Environmental Medicine for welcoming me to the clinic and always being so friendly and helpful.

Riccardo Barchiesi for all the years since I got to Linköping and for always being there. Chris Sackmann for being a great friend, all the late-night sports and weird Canadian TVshows. Valerie Sackmann for being a good friend, host and always cooking such delicious meals. Cynthia Veenstra for all help, being a great friend and spreading joy. Emelie Blixt for being a great friend over the years and the fun times. Antonio Lentini and Robert Lindau for being good friends and company during the US/Canada trip. Jonathan Rakar for taking me in as a student all those years ago and the squash-games. Åsa Jufvas for help with, as well as sharing the frustration at, the mass spectrometers. Anneli Tinnerholm and Christine Klar for being good friends.

The DOMFIL board with Angelika Holm, Olof Sandberg, Linda Bojmar and Mikaela Ridelberg for the fun, but exhausting, year in the board and being good friends. The DOMFIL floorball crew for the attempt to keep my stamina in check and the twisted ankles. The Medical Faculty Appointments Board for the worthwhile years as a representative.

$\mathrm{PhD}$ students and other people, with who I had the opportunity to spend time with.

All my family with parents, extra-parents, siblings with significant others, nephews/nieces, grandma and in-laws. You help me focus on other stuff than research and liven up the holidays.

Therese, my wife, soul mate and best friend. Ord räcker inte till för hur mycket du betyder för mig. Jag är dig evigt tacksam för att du stått ut med mig genom alla dessa år. Jag ser fram emot vår gemensamma framtid tillsammans med Pricken. 


\section{Papers}

The articles associated with this thesis have been removed for copyright reasons. For more details about these see:

http://urn.kb.se/resolve?urn=urn:nbn:se:liu:diva-131643 